\title{
The Site of Spontaneous Ectopic Spike Initiation Facilitates Signal Integration in a Sensory Neuron
}

\author{
[Carola Städele ${ }^{1,2}$ and $\odot$ Wolfgang Stein ${ }^{2}$ \\ ${ }^{1}$ Institute of Neurobiology, Ulm University, 89069 Ulm, Germany, and 2School of Biological Sciences, Illinois State University, Normal, Illinois 61790
}

Essential to understanding the process of neuronal signal integration is the knowledge of where within a neuron action potentials (APs) are generated. Recent studies support the idea that the precise location where APs are initiated and the properties of spike initiation zones define the cell's information processing capabilities. Notably, the location of spike initiation can be modified homeostatically within neurons to adjust neuronal activity. Here we show that this potential mechanism for neuronal plasticity can also be exploited in a rapid and dynamic fashion. We tested whether dislocation of the spike initiation zone affects signal integration by studying ectopic spike initiation in the anterior gastric receptor neuron (AGR) of the stomatogastric nervous system of Cancer borealis. Like many other vertebrate and invertebrate neurons, AGR can generate ectopic APs in regions distinct from the axon initial segment. Using voltagesensitive dyes and electrophysiology, we determined that AGR's ectopic spike activity was consistently initiated in the neuropil region of the stomatogastric ganglion motor circuits. At least one neurite branched off the AGR axon in this area; and indeed, we found that AGR's ectopic spike activity was influenced by local motor neurons. This sensorimotor interaction was state-dependent in that focal axon modulation with the biogenic amine octopamine, abolished signal integration at the primary spike initiation zone by dislocating spike initiation to a distant region of the axon. We demonstrate that the site of ectopic spike initiation is important for signal integration and that axonal neuromodulation allows for a dynamic adjustment of signal integration.

Key words: axon physiology; ectopic spike initiation; octopamine; optical imaging; signal integration; stomatogastric

\section{Significance Statement}

Although it is known that action potentials are initiated at specific sites in the axon, it remains to be determined how the precise location of action potential initiation affects neuronal activity and signal integration. We addressed this issue by studying ectopic spiking in the axon of a single-cell sensory neuron in the stomatogastric nervous system. Action potentials were consistently initiated at a specific region of the axon trunk, near a motor neuropil. Spike frequency was regulated by motor neuron activity, but only if spike initiation occurred at this location. Neuromodulation of the axon dislocated the site of initiation, resulting in abolishment of signal integration from motor neurons. Thus, neuromodulation allows for a dynamic adjustment of axonal signal integration.

\section{Introduction}

The ability of neurons to properly initiate action potentials (APs) is fundamental for nervous system function and information processing. Although the properties of spike initiation zones (SIZs) have been associated with the cells' information-

Received July 20, 2015; revised May 10, 2016; accepted May 16, 2016.

Author contributions: C.S. and W.S. designed research; C.S. and W.S. performed research; C.S. and W.S. analyzed data; C.S. and W.S. wrote the paper.

This work was supported by German Research Foundation Grants DFG STE 937/9-1 and NSF IOS 1354932, Illinois State University, and the German Academic Exchange Service. We thank Dr. Peter Andras for help with initial data collection in his laboratory.

The authors declare no competing financial interests.

Correspondence should be addressed to Dr. Wolfgang Stein, School of Biological Sciences, Illinois State University, Normal, IL 61790. E-mail: wstein@neurobiologie.de.

DOI:10.1523/JNEUROSCI.2753-15.2016

Copyright $\odot 2016$ the authors $\quad 0270-6474 / 16 / 366718-14 \$ 15.00 / 0$ processing capabilities (Colbert and Pan, 2002; Kuba et al., 2006, 2007; Palmer and Stuart, 2006; Shu et al., 2007; Lorincz and Nusser, 2008), few studies have addressed whether the precise location of the SIZ affects neuronal activity and the encoding properties of neurons. The location of SIZs can depend on cell type (Kole et al., 2007; Shu et al., 2007; Schmidt-Hieber et al., 2008) and appears to be functionally important for neuronal signal processing (Kole et al., 2007; Shu et al., 2007; Schmidt-Hieber et al., 2008). In the avian auditory system, for example, the location of the SIZ supports different sensitivities to interaural time differences between neurons (Carr and Boudreau, 1996; Kuba et al., 2006; Kuba et al., 2014). There are also indications that longterm changes in electrical activity can lead to a homeostatic dislocation of the SIZ to restore neuronal activity (Grubb and Burrone, 2010; Kuba et al., 2010). Changes in the location of spike initiation thus appear to contribute to neuronal plasticity, 

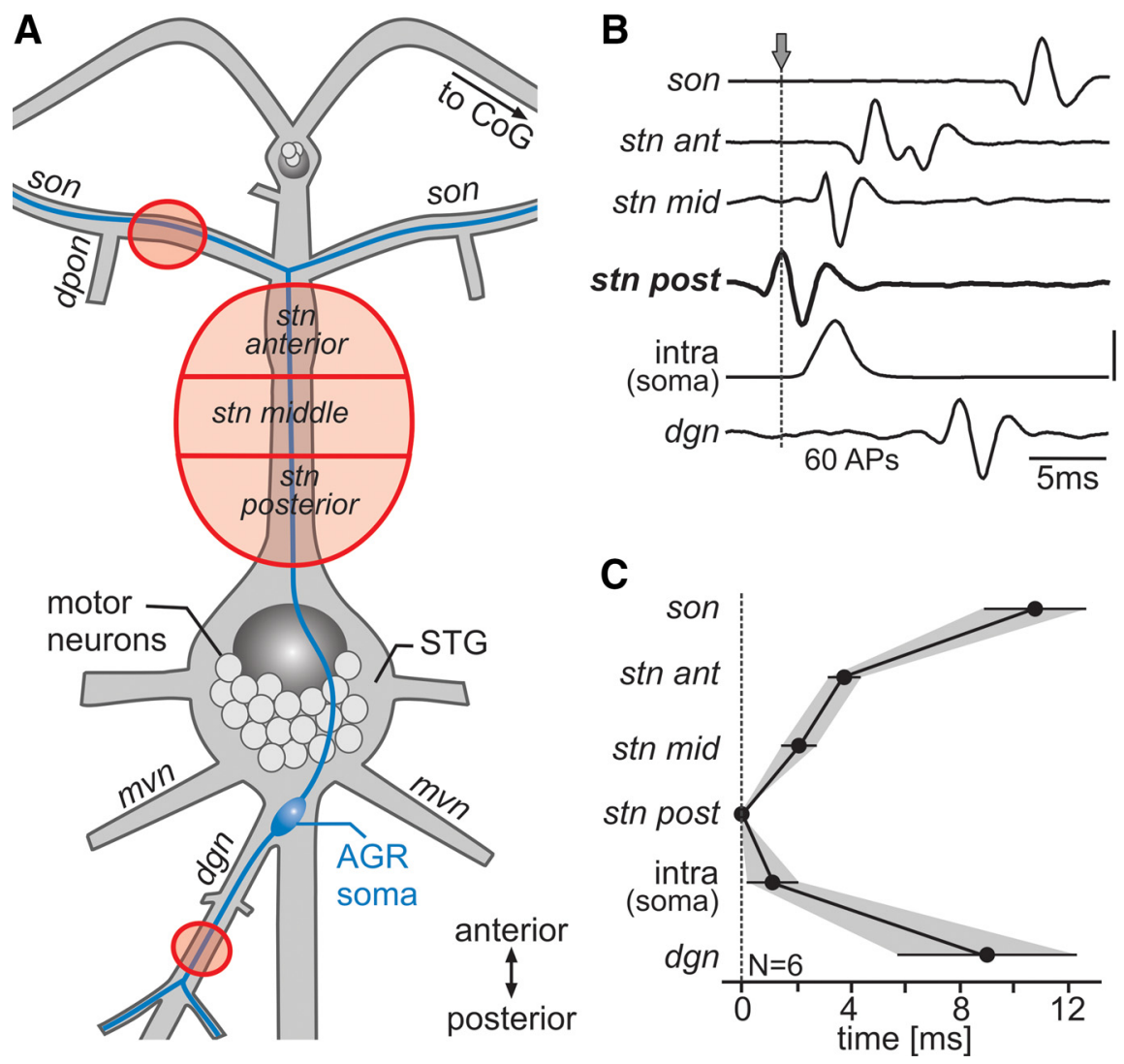

Figure 1. AGR's ectopic APs are consistently elicited at a fixed location. $A$, Schematic of the stomatogastric nervous system with AGR and its axonal projections depicted in blue. Red circles represent the extracellular recording sites. Nerve names are italicized. $B$, Averages (60 APs each) of AGR spike activity showing the spike conduction along 5 extracellular recording sites as depicted in $A$, plus an intracellular recording from the AGR soma. Intracellular AGR spikes from the soma were used as trigger. The AGR spike occurred first on the stn posterior recording (indicated in bold), showing that AGR's eSIZ was closer to the stn recording site than to the soma. Scale bar: $40 \mathrm{mV}$. C, Analysis of the AP latency for 6 experiments. Data are mean \pm SD. The recording site where APs occurred first was set to time 0 . In all experiments, the AGR spike occurred first on the posterior stn recording. The larger SD on the dgn and son recordings are attributable to slightly different positions of recording wells (and thus latencies) between experiments. Nerves: son, superior esophageal nerve; stn, stomatogastric nerve; mvn, medial ventricular nerve; dgn, dorsal gastric nerve; dpon, dorsal posterior esophageal nerve. CoG, Commissural ganglion.

but very little evidence exists that this potential mechanism for plasticity is exploited in a more dynamic fashion.

We here demonstrate that axonal neuromodulation allows a dynamic dislocation of the SIZ resulting in altered signal integration. For our studies, we use the axon of the anterior gastric receptor (AGR) neuron (Combes et al., 1995), a single-cell muscle tendon organ in the stomatogastric nervous system of crustaceans. In the Jonah crab (Cancer borealis), part of the normal activity repertoire of AGR is the generation of spontaneous tonic spike activity in its axon trunk, far away from its sensory dendrites (ectopic spike initiation) (Smarandache and Stein, 2007; Smarandache et al., 2008; Hedrich et al., 2009). Ectopic AP initiation is prevalent in at least some invertebrate and mammalian axons, influencing the neurons' signal processing abilities (Calabrese, 1980; Maranto and Calabrese, 1984; Pinault, 1990; Meyrand et al., 1992; Bostock and Bergmans, 1994; Kiernan et al., 1997; Bucher et al., 2003; Goaillard et al., 2004; Lang et al., 2006; Papatheodoropoulos, 2008; Sheffield et al., 2011). Ectopic spikes can be initiated by application of neuromodulators, such as amines or peptides (for review, see Pinault, 1995; Bucher and Goaillard, 2011), but some neurons spontaneously generate ectopic spike activity in the axon trunk (Maranto and Calabrese, 1984; Pinault, 1990; Daur et al., 2009; Sheffield et al., 2011). How ectopic spike frequency in axon trunks is controlled is often not clear. In most cases, it is even unclear where the ectopic spike initiation zones (eSIZs) are located and why they are there.

Here, we addressed whether spontaneous ectopic spiking is consistently generated at a specialized axonal region, whether the site of spike initiation is altered in different conditions, and whether this affects signal integration and neuronal function. Using voltage-sensitive dyes, we identified the precise location of AGR's eSIZ in the axon trunk. The eSIZ was consistently found near axonal arborizations in the neuropil region of the stomatogastric ganglion (STG), in close vicinity to potential postsynaptic partners. Indeed, AGR's ectopic spike frequency was influenced locally by gastric mill (GM) motor neurons. This sensorimotor interaction was state-dependent: focally applied octopamine (OA), the invertebrate analog of norepinephrine, excited the AGR axon membrane and effectively shifted the eSIZ away from the site of synaptic input. In this condition, sensorimotor interactions were abolished. Our results thus demonstrate that the site of spike initiation is important for axonal signal integration and that neuromodulation dynamically gates signal integration in axons.

\section{Materials and Methods}

Dissection. Adult male crabs (C. borealis) were purchased from the Fresh Lobster Company or Ocean Resources and kept in tanks with artificial sea water (salt content $\sim 1.025 \mathrm{~g} / \mathrm{cm}^{3}$, Instant Ocean Sea Salt Mix) at $11^{\circ} \mathrm{C}$ and a $12 \mathrm{~h}$ light/dark cycle. Before dissection, animals were anesthetized on ice for 20-40 min. All experiments were performed in vitro on isolated nervous systems. The stomatogastric nervous system was isolated from the animal following standard procedures (Gutierrez and Grashow, 2009), pinned out in a silicone lined (Wacker) Petri dish, and continuously superfused $(7-12 \mathrm{ml} / \mathrm{min})$ with physiological saline $\left(10^{\circ} \mathrm{C}-12^{\circ} \mathrm{C}\right)$.

Solutions and modulators. C. borealis saline was composed of the following (in mM): $440 \mathrm{NaCl}, 26 \mathrm{MgCl}_{2}, 13 \mathrm{CaCl}_{2}, 11 \mathrm{KCl}, 11.2$ Trisma base, 5.1 maleic acid, pH 7.4-7.6 (Sigma Aldrich). High-divalent saline (HiDi) contained 5 times the amount of $\mathrm{Ca}^{2+}$ and $\mathrm{Mg}^{2+}$ than the regular saline and was composed of the following (in $\mathrm{mm}$ ): $440 \mathrm{NaCl}, 130 \mathrm{MgCl}_{2}, 65$ $\mathrm{CaCl}_{2}, 11 \mathrm{KCl}, 11.2$ Trisma base, 5.1 maleic acid, $\mathrm{pH}$ 7.4-7.6. This saline raises AP threshold in the stomatogastric nervous system, thereby suppressing the spontaneous activity of many neurons, including AGR (Daur et al., 2009) and reducing the activation of polysynaptic pathways (Blitz and Nusbaum, 1999). OA hydrochloride (Sigma Aldrich) was dissolved in ultrapure water and stored as concentrated stock solutions $(10 \mathrm{~mm})$ at $-20^{\circ} \mathrm{C}$. Immediately before an experiment, stock solutions were diluted in saline to the desired concentration $(50 \mu \mathrm{M})$.

Neuromodulator application. Petroleum-jelly wells were used to isolate the application site from the rest of the nervous system. OA was cooled to $10^{\circ} \mathrm{C}-12^{\circ} \mathrm{C}$ and either superfused to the whole stomatogastric nerve (stn) or manually applied to the anterior part of the $\sin$ (close to the $s t n / s o n$ junction; Fig. $1 A$ ). As a control, saline was applied at the same temperature $5 \mathrm{~min}$ before each neuromodulator application. Measurements were taken in steady state (2-5 min after OA wash in). To prevent cumulative 
effects due to repeated modulator application, washouts were 10-20 minutes long with continuous superfusion of cooled saline.

To dislocate AGR's eSIZ, high-divalent saline was superfused to the entire stn. In some experiments, HiDi was also specifically applied to the posterior stn, where the SIZ is located. This did not affect STG motor and interneurons, and gastric mill activity could reliably be elicited by ventral cardiac neuron (VCN) stimulation. AGR spike activity was monitored extracellularly in the anterior part of the $\operatorname{stn}$ (close to the $s t n / s o n$ junction). This part was not affected by HiDi.

Extracellular and intracellular recordings. Standard techniques were used for extracellular and intracellular recordings (Stein et al., 2005). Because desheathing the STG influences the modulation of AGR's ectopic spiking (Goldsmith et al., 2014), most experiments were performed using nondesheathed nervous system preparations and extracellular recording techniques (exceptions were imaging and intracellular recording/dye injection experiments). For extracellular recordings, we used petroleum jelly-wells to electrically isolate a small part of the nerves from the surrounding bath. One of two stainless-steel electrodes was placed inside the well to record neuronal activity of all axons projecting through a particular nerve. The other wire was placed in the bath as reference electrode. Extracellular signals were recorded, filtered, and amplified through an amplifier (AM Systems, Model 1700). The activity of AGR was monitored on multiple extracellular recordings simultaneously, namely, on the stn (anterior, middle, and posterior), the dorsal gastric nerve $(d g n)$, and the supraesophageal nerve (son; see Figure $1 A)$. To perform multiple recordings along the $s t n$, the whole length of the nerve (on average, $1.25 \pm 0.27 \mathrm{~cm}, N=16$ ) was divided in three parts of equal length. Each recording well had an inner diameter of $\sim 300-400 \mu \mathrm{m}$. AGR is easily detectable on the dgn recording, as this nerve contains only a few units. In addition, AGR is typically the largest unit on the stn, which in total contains $>50$ units (Coleman et al., 1992). To identify AGR on the different recording sites, we used APs recorded on the dgn or stn and performed a time-correlation analysis (multisweep). AGR activity was measured as instantaneous firing frequency (inst. ff.) as determined by reciprocal of the interspike interval. GM neuron activity was monitored either on a side branch of the $d g n$, exclusively containing GM axons, or on the $m v n$ (Fig. 1A).

To facilitate intracellular recordings and dye injections, we desheathed the STG and visualized STG somata with white light transmitted through a dark field condenser (Nikon). Intracellular recordings were obtained from cell bodies using 20-30 $\mathrm{m} \Omega$ glass microelectrodes (Sutter 1000 puller, $0.6 \mathrm{M} \mathrm{K}_{2} \mathrm{SO}_{4}+20 \mathrm{~mm} \mathrm{KCl}$ solution) and an Axoclamp 900A amplifier (Molecular Devices) in current-clamp mode. Files were recorded, saved, and analyzed using Spike2 Software at $10 \mathrm{kHz}$ (version 7.12; CED). For dye injections, electrode tips were filled with $10 \mathrm{~mm}$ AlexaFluor-568 or AlexaFluor-488 (Invitrogen) in $200 \mathrm{~mm} \mathrm{KCl}$. Repetitive negative current pulses ranging between -3 and $-5 \mathrm{nA}$ with pulse durations of 1-2 s were used to iontophoretically inject the dye.

Extracellular axon stimulation. We used retrograde extracellular nerve stimulation to activate all 4 GM neurons simultaneously. A petroleumjelly well was built around one of the branches, leaving the $d g n$ that contains exclusively axons of GM neurons. One of two stainless-steel stimulation electrodes was placed inside the compartment, and the other was placed outside. APs were elicited with 30 stimulus trains each of 25 or $40 \mathrm{~Hz}$ stimulation frequency, $10 \mathrm{~s}$ stimulus train, 10-20 s intertrain intervals, and $1 \mathrm{~ms}$ pulse duration. Frequencies and pattern were selected based on GM activity in vivo (Smarandache et al., 2008) and in vitro (this study: $32 \pm 11 \mathrm{~Hz}, N=16$ ), which ranges between 10 and $40 \mathrm{~Hz}$ per neuron. Stimulation durations reflect the mean gastric mill duty cycle $(55 \pm 8 \%, N=16)$ and gastric mill cycle period ( $15 \pm 9 \mathrm{~s}, N=16)$.

In some experiments, gastric mill rhythms were elicited by activating the VCN neurons. The VCN neurons were activated by stimulating the dorsal posterior esophageal nerve (dpon) extracellularly with 10 consecutive stimulus trains of $15 \mathrm{~Hz}$ stimulation frequency, $6 \mathrm{~s}$ stimulus train, 4 s intertrain intervals, and $1 \mathrm{~ms}$ pulse duration (Beenhakker et al., 2004).

Voltage-sensitive dye preparation and application. For optical imaging, the lipophilic voltage-sensitive dyes Di-4-ANEPPS (Fluhler et al., 1985) and Di-4-ANNEPDHQ (Obaid et al., 2004) (both from Invitrogen) were used. Stock solutions ( $5 \mathrm{~mm}$ ) were prepared by diluting dyes in DMSO
(Sigma-Aldrich) and stored in small quantities $(2 \mu \mathrm{l})$ at $-20^{\circ} \mathrm{C}$, protected from light. Immediately before an experiment, Pluronic F-127 $20 \%$ solution in DMSO (Biotium) was added 1:1 to the stock solution to obtain a final concentration of $2.5 \mathrm{~mm}$ dye with $10 \%$ Pluronic. Dyes were diluted further to a working concentration of $50 \mu \mathrm{M}$ in saline. To facilitate access of the dye to the STG neurons and stn axons, the connective tissue from the ganglion and the nerve was removed. A petroleum-jelly well was built around the STG and stn, and $200 \mu \mathrm{l}$ of either dye was applied into the well. Other parts of the stomatogastric nervous system were constantly superfused with chilled saline $\left(10^{\circ} \mathrm{C}-12^{\circ} \mathrm{C}\right)$ during dye application. After $30 \mathrm{~min}$, the well was removed and washout started for 15-20 min. During the remainder of the experiment, all parts of the preparation were continuously superfused with chilled saline $\left(10^{\circ} \mathrm{C}-12^{\circ} \mathrm{C}\right)$.

Optical imaging. For optical imaging, changes in fluorescence signal were measured using the MiCam02 imaging system and BVAna Software (version 13.07.04.8, SciMedia) with a high-resolution camera $(6.4 \times 4.8$ $\mathrm{mm}$ actual sensor size). Spatial resolution was $48 \times 32$ pixels with $1.3 \mathrm{~ms}$ temporal resolution and $28 \mathrm{~s}$ recording length. We used event-triggered averaging of APs to improve the signal-to-noise ratio of the optically recorded data, similar to Städele et al. (2012). Because of AGR's low firing frequency $(2-5 \mathrm{~Hz})$, recordings were repeated 3 times on a given ROI to gather enough data for averaging. Excitation $(470 \mathrm{~nm}$ and $535 \mathrm{~nm})$ was provided by a LED-illumination system (PE-100, CoolLED) with 525 $\mathrm{nm} / 50 \mathrm{~nm}$ bandwidth and $605 \mathrm{~nm} / 70 \mathrm{~nm}$ bandwidth excitation filters (Olympus). Fluorescence was detected with a $20 \times$ objective (XLUMPlanFL N, NA 1.0, WD $2.0 \mathrm{~mm}, \mathrm{cc}=$ water; Olympus) mounted on an upright epifluorescence microscope (modified BX51, Scientifica). Illumination during optical imaging was $5 \%-25 \%$ of the maximum LED strength. The position of recording sites, and the AGR axon in the stn was reconstructed with high-resolution pictures $(384 \times 256$ pixels $)$ and via tracing the position of the motorized microscope stage (SlicePlatform Pro 2000, Scientifica) and the associated software (LinLab, version 2).

Imaging data were collected for many locations along the axon trunk. Specifically, imaging started at the anterior end of the stn and ended at the anterior end of the STG, where the neuropil starts (Di-4-ANEPPS) or the posterior end of the STG, where the motor nerves are leaving the ganglion (Di-4-ANNEPDHQ). After each recording trial, the objective was moved to a more posterior recording site. Extracellular recordings of the $d g n$ and son were used to monitor AGR's spike activity during optical imaging and to perform time comparison analyses for identifying the location of spike generation.

Calculation of conduction velocity. To determine the conduction velocity of AGR's central axon, we measured the time difference of spike occurrences between extracellular recordings at the anterior stn and the son by averaging across multiple AGR APs $(\geq 60)$. We used the anterior stn and son for calculating the conduction velocity because the AP is not generated in between those recording sites but rather passes the recording sites one after the other. The location of the recording sites was photographed, and the distance was analyzed using ImageJ (National Institutes of Health). Conduction velocity was calculated by dividing the time difference between son and stn by the distance between recording sites.

Data analysis, statistics, and figure preparation. Data were analyzed using scripts for Spike2 (available on www.neurobiologie.de/spike2) and by using built-in software functions. In some experiments, spiketriggered averaging was used to improve signal quality of both extracellular and optical imaging data according to Städele et al. (2012). For spike detection, a voltage threshold was used and the subsequent maximum or minimum voltage deflection of the signal passing through this threshold was used as trigger. In cases where extracellular stimulus artifacts or the APs of other neurons obscured the neuron of interest, obscuring signals were eliminated from recordings using a sliding average script in Spike2. For analysis, AGR inst. ff. was normalized to the control frequencies measured before stimulation and plotted as a function of the normalized cycle period of the GM neurons (phase). Mean values of 10 consecutive GM cycles were measured in each animal. AGR inst. ff. was binned over phase with a bin size of 0.1 , and the mean \pm SD of several animals was plotted. One-way repeated-measures ANOVA was used to assess changes 
in AGR firing frequency in response to stimulation of the VCN or GM neurons. Pairwise comparisons were performed using Holm-Sidak post hoc tests with $p<0.05$ significance level. All tests were computed in SigmaPlot (version 12 for Windows, Systat Software) and significant differences are indicated using ${ }^{*} p<0.05,{ }^{* *} p<0.01$, and ${ }^{* * *} p<0.001$. $N$ indicates the number of preparations. Final figures were prepared with CorelDRAW Graphics Suite (version X7, Corel).

\section{Results}

\section{Spontaneous ectopic spikes are consistently initiated at a fixed location}

AGR is a bipolar sensory neuron in the crustacean stomatogastric nervous system (Fig. 1A) (Combes et al., 1995, 1997; Smarandache and Stein, 2007; Daur et al., 2009). In C. borealis, part of AGR's normal activity repertoire is the generation of spontaneous tonic ectopic spike activity (in vivo and in vitro) (Smarandache et al., 2008; Daur et al., 2009). Ectopic spiking occurs as soon as sensory spikes from the periphery are absent (i.e., ectopic spikes are present at rest and in-between bursts generated in the periphery). Although it has been shown that ectopic spikes are generated anterior to the AGR soma in the stomatogastric nerve (stn) (Daur et al., 2009), it is unknown where in this severalcentimeters-long nerve ectopic spikes are initiated and whether spike initiation consistently occurs at a fixed location across animals.

To investigate whether the location where ectopic spikes are initiated determines the function of these APs, we first studied where in the stn spike initiation occurs. We used multiple extracellular recordings along the AGR axon plus an intracellular soma recording to compare the temporal spike occurrence between recording sites. Specifically, we recorded AGR activity in the periphery on the $d g n$, at three sites along the $\operatorname{stn}$ (posterior, middle, anterior) and close to the commissural ganglia on the sons (Fig. 1A). We found that AGR's spontaneous APs always occurred first on the stn posterior recording site (Fig. 1B). APs propagated orthodromically from the posterior stn toward the anterior stn and son and antidromically toward the dgn. Across preparations, spikes consistently occurred first on the stn posterior recording site $(N=6$; Fig. $1 C)$, on average $1.12 \pm 0.9 \mathrm{~ms}$ earlier than at the soma. Our data thus show that AGR's ectopic spikes were consistently initiated in a region comprising the posterior part of the stn and the STG neuropil.

\section{Identifying the location of AGR's eSIZ in the axon using light- induced activation of ectopic spiking}

Extracellular electrophysiological methods have a rather limited spatial resolution due to the size of the electrodes and the required space for electrode placement $(>8 \mathrm{~mm})$. Consequently, time differences in AP latency between extracellular electrodes cannot provide an adequate estimate of the spike initiation site. One would ideally record simultaneously from multiple axonal sites intracellularly, a challenging task because of the difficulty to access the small-diameter axon. To overcome these experimental restrictions of electrophysiology, we used an approach that enabled us to determine the site of AGR's eSIZ with a spatial resolution of $225 \mu \mathrm{m}$. We used voltage-sensitive dyes to optically excite AGR's axon membrane at specific spots along the stn to artificially move the site of spike initiation away from the spontaneous (primary) eSIZ. A shift of the eSIZ resulted in a change in spike arrival times between recording sites, which was used to determine the location of the primary eSIZ. For this, the STG and stn were stained with the voltage-sensitive dye $\mathrm{Di}-4$ ANNEPDHQ (Obaid et al., 2004). The excitation light (535 nm,
$605 \mathrm{~nm} / 70 \mathrm{~nm}$ bandwidth) was focused with a pinhole such that an area with a diameter of $225 \mu \mathrm{m}$ was illuminated. We found that illuminating the stained axons increased AGR firing frequency (Fig. 2A). Excitatory side effects of lipophilic VSDs have been reported previously (Stein and Andras, 2010; Preuss and Stein, 2013), and while usually undesired, they were instrumental in our efforts to locate the SIZ. We found that illumination caused a change in AP latency ( $\Delta$ delay, Fig. $2 B$ ) between extracellular recording sites indicating that a new eSIZ was generated at the illuminated spot. This effect was reversible, i.e., when illumination was turned off the primary eSIZ became active again and continued to generate APs at the primary location (Fig. 2Biii). We moved the site of illumination posteriorly along the $s t n$ to create new artificial spike initiation sites at various axonal locations. Simultaneously, we recorded AGR spike occurrence extracellularly on the $d g n$ and son to detect changes in spike timing between these recording sites. The location of the primary SIZ was reached when illumination did not alter the timing of the APs compared with control situations (Fig. $2 C$, red trace). All of our experiments $(N=4)$ show that the eSIZ was located at the anterior border of the STG neuropil (Fig. 2D). To compare the location of the eSIZ across multiple experiments, we defined the anterior end of the STG neuropil as position 0 . Negative values correspond to positions posterior to the neuropil border, positive values to positions in the $s t n$. Across preparations, the position of the eSIZ varied only slightly. In three preparations (Fig. $2 D, 1-3$ ), there was exactly one location where illumination was ineffective in moving the spike initiation site (indicated by arrow). Illumination of further anterior or posterior spots resulted in clear changes in AP latencies. In preparation 4, illumination of two successive spots did not significantly alter AP latency, indicating that the eSIZ extended to both illumination sites. On average, spike delays were significantly different from control in areas outside of 225 and $-225 \mu \mathrm{m}$ from the anterior neuropil border. Thus, the primary eSIZ was consistently located at the anterior border of the STG neuropil. Interestingly, the variability in the timing of the ectopic spikes ("jitter") increased with distance from the spontaneous eSIZ (Fig. 2C). This may indicate that the location of spike initiation is rather spatially restricted at the primary eSIZ, whereas at more distant axon locations APs were elicited at multiple positions within the $225 \mu \mathrm{m}$ that were illuminated.

In summary, our results show that the spontaneous eSIZ was spatially restricted and consistently located near the anterior end of the STG neuropil.

\section{Confirming the location of AGR's eSIZ using optical imaging} Because optical excitation of axonal spike initiation is a novel technique developed by us and had never been used before, we wished to confirm our findings using a different approach. To this end, we used optical imaging with voltage-sensitive dyes along the axon to determine the timing of ectopic APs along the axon. For optical imaging to be successful, the object of interest has to be in focus. The AGR axon can be found ventrally in the STG, and it leaves the STG neuropil ventrally to enter the $\operatorname{stn}$ (Goeritz et al., 2013). However, whether the AGR axon is consistently found ventral, medial, or dorsal in the stn is unknown. We thus first determined the dorsoventral position of AGR's axon in the stn. To do this, we injected a fluorescent marker (AlexaFluor-488) into the AGR soma and traced the axon in the stn with a counterstaining of Di-4ANEPPS (Fig. 3A). The stn contains $\sim 56$ large-diameter axons (Coleman et al., 1992). These axons were easily recognizable after staining with the voltage-sensitive dye, but they were 
A

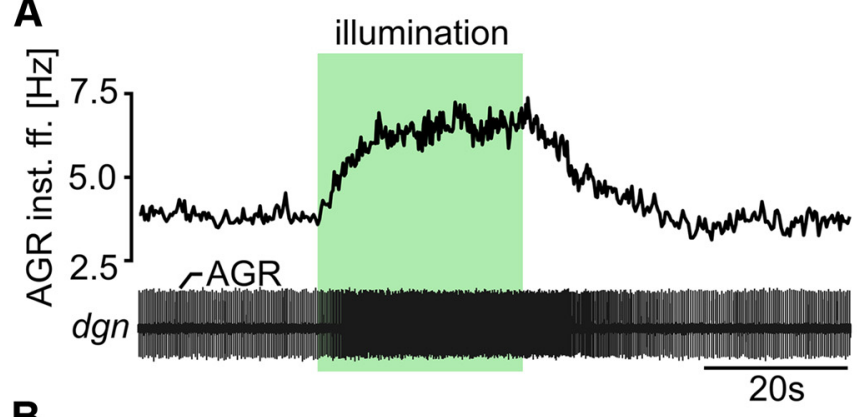

B

i: control, pre-illumination

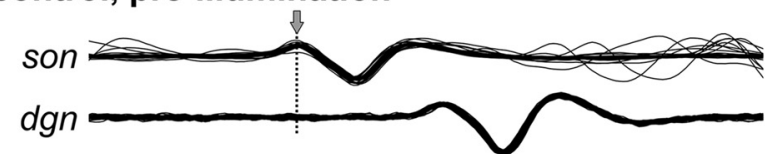

ii: during illumination

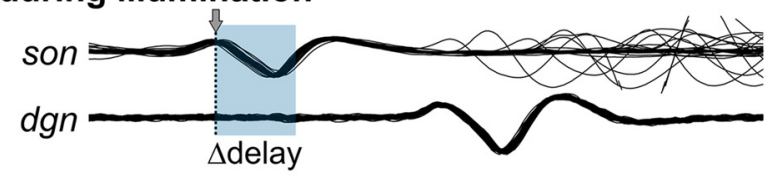

iii: control, post-illumination

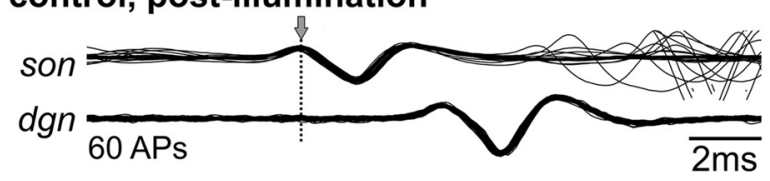

D

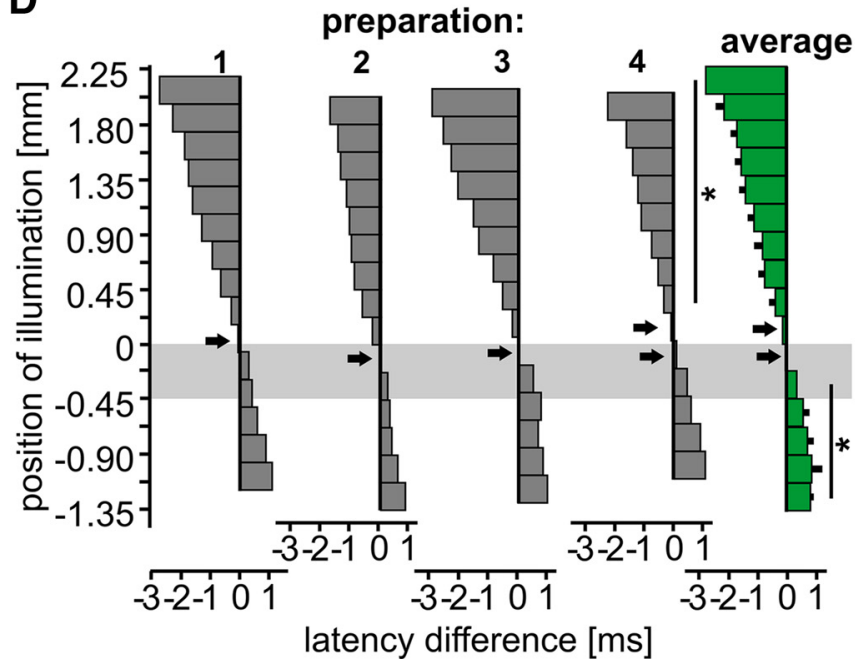

C

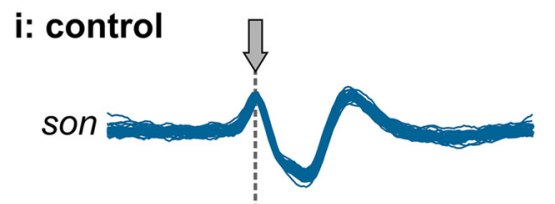

\section{ii: during illumination}

ำ

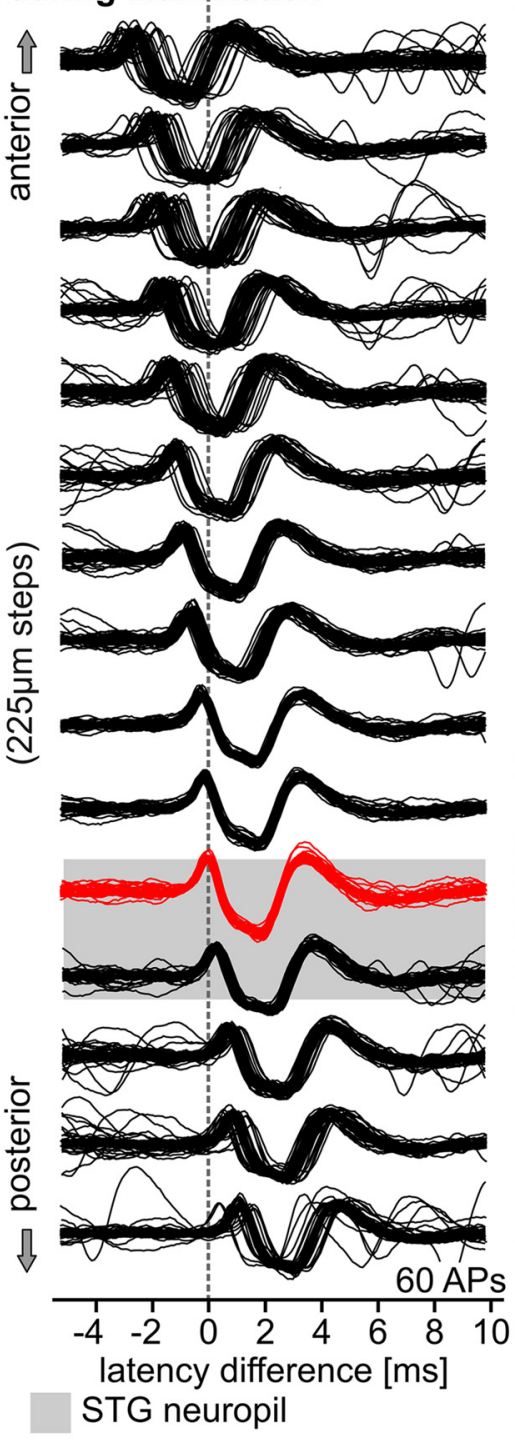

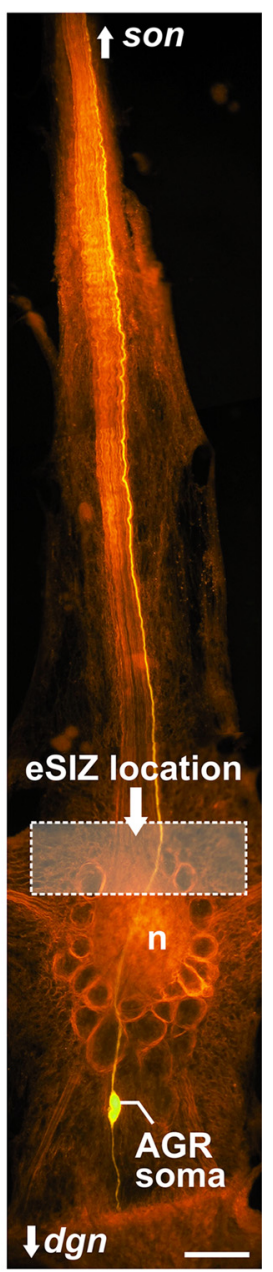

Jdgn

Figure 2. Identifying AGR's eSIZ via light-induced activation of ectopic spiking. A, AGR instantaneous firing frequency (inst. ff., top) and original recording of AGR activity on the dgn (bottom). Illumination of the stn after bath application of the VSD Di-4-ANNEPDHQ increased AGR inst. firing frequency. The length of the illuminated area was $225 \mu \mathrm{m}$. $\boldsymbol{B}, 0$ verlay of multiple AGR APs before, during, and after illumination (60 APs each). During illumination, the spike delays between $d g n$ and stn recordings changed (depicted as $\Delta$ delay), indicating that the eSIZ moved to a different location. C, Comparison of AGR spike latency on the son relative to the $d g n$ when different areas of the stn were illuminated. Traces are overlays of $60 \mathrm{APs}$ each. The eSIZ traveled with the optical stimulus; and only when the STG neuropil was reached, no change in latency compared with control (blue trace, top) was found. Right, Composite photo of AGR (AlexaFluor-568) and STG and stn (Di-4-ANNEPDHQ). White box represents the area of spike initiation. n, Neuropil. Scale bars, $100 \mu \mathrm{m}$. D, Deviation of AP latency on the son during illumination of different stn areas (225 $\mu \mathrm{m}$ each). Shown are four experiments (gray) plus average (green, mean \pm SD). Gray box represents the location of the STG neuropil. Position zero represents the anterior border of the STG, with negative values corresponding to more posterior areas and positive values to more anterior areas (stn). *Areas where illumination caused a significant change to control (one-way ANOVA, $p<0.001, F_{(3,15)}=132.177$, Holm-Sidak post hoc test with $\left.p<0.05, N=4\right)$. Arrows indicate areas without significant change to control.

distributed across several vertical focal planes (4-6 clearly distinguishable focal planes with a total axon bundle diameter of $\sim 25 \mu \mathrm{m})$. The AGR axon was always found in the most ventral part of the axon bundle $(N=6)$.

To identify the location of AGR's eSIZ, we compared AP latencies of optically recorded APs to an extracellular recording of the same APs on the dgn. We stained the stn with the fast voltagesensitive dye Di-4-ANEPPS and performed optical recordings at different sites along the AGR axon, starting at the anterior stn (close to the $s t n / s o n$ junction). In contrast to the dye we used for light-induced activation of ectopic spiking (Di-4-ANNEPDHQ), Di-4-ANEPPS has little to no excitatory effect when illuminated 


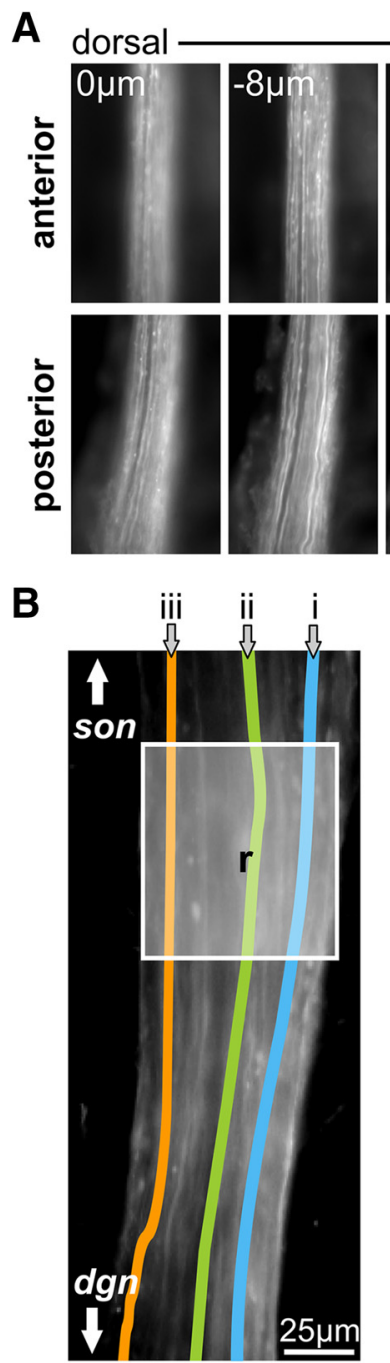

D

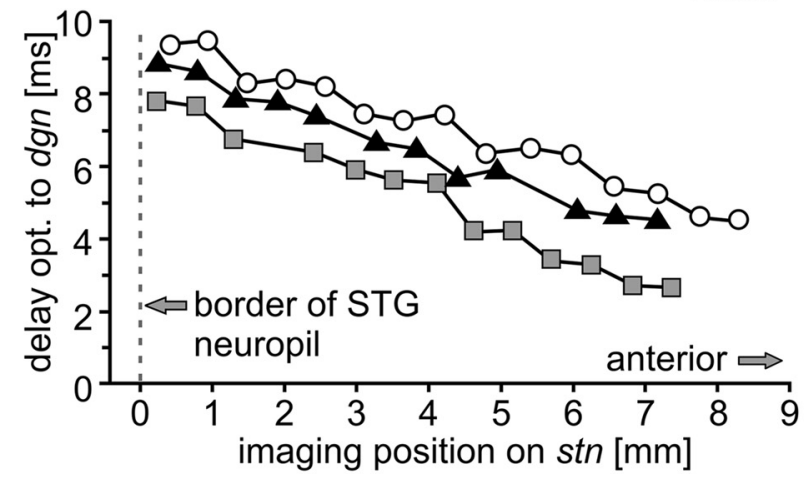

opt.

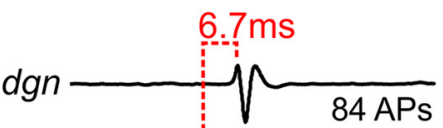

i: $\operatorname{axon} 1$

opt.

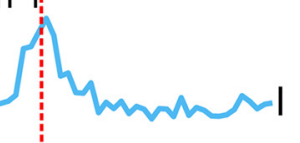

ii: axon 2

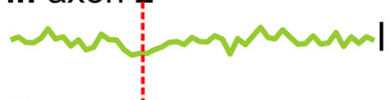

opt.

iii: axon 3

$$
\text { r: rectangle }
$$<smiles>O[14CH2]CCCCCCCCCCCCCCCI</smiles>

iv: $r$ minus axon 1
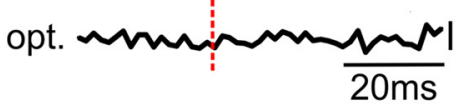

C

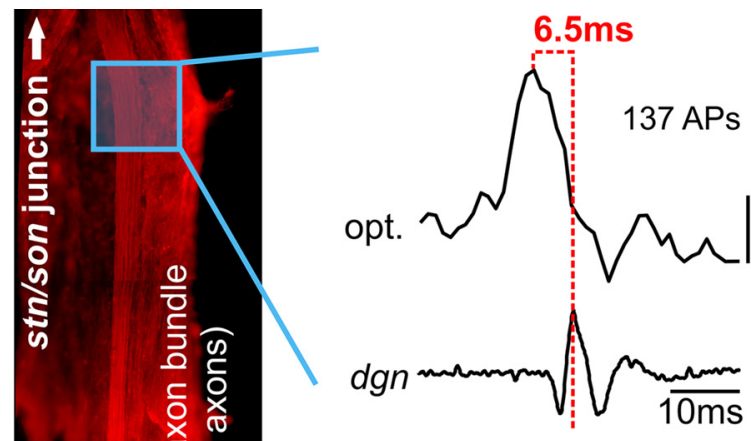

Figure 3. Confirming the location of AGR's eSIZ using optical imaging. A, Z-stack of photos showing axons projecting through the stn for 5 different focal planes (left represents dorsal; right represents ventral, $8 \mu \mathrm{m}$ steps). Photos were taken at the anterior stn (top, $4386 \mu \mathrm{m}$ away from the STG neuropil) and posterior stn (bottom, $527 \mu \mathrm{m}$ from away from neuropil). The stn was desheathed and stained with Di-4-ANNEPS. The AGR axon was visualized via intrasomatic AlexaFluor-488 injection. The AGR axon (arrow) was consistently found in the most ventral part of the axon bundle. All axons in the $-30 \mu \mathrm{m}$ focal plane are out of focus (i.e., this focal plane was more ventral than the axon bundle). Scale bars, $50 \mu \mathrm{m}$. B, Optical recordings of AGR's spike activity in the stn (3.3 mm anterior of the STG neuropil). Left, High resolution picture. Different ROls were selected (Bi-iii, axons 1-3; $r$, Rectangular region) and the change in fluorescence of all pixels within a given ROI was analyzed. Right, Averaged optical signals (opt, averages of 84 APs) triggered on the extracellular AGR AP on the dgn (top). In the example shown, traces from axon 1 ( $\boldsymbol{i}$ ) and the rectangle ( $r$ ) showed that fluorescence changes correlated with the AGR AP on the dgn recording. As control, when the fluorescence signal of axon 1 was subtracted from the rectangle (Biv), no peak remained, indicating that those regions contained the AGR axon. The conduction delay between the optical recordings and the dgn is depicted in red. Vertical scale bars: $0.1 \%$ fluorescence change. C, Optical imaging along the stn. Left, Composite photograph of STG and stn after staining with Di-4-ANNEPS, showing the location of three selected optical recording sites (blue squares). Right, Averaged optical signal (top) and extracellular dgn recording (bottom) for the three depicted recording sites. The delay between the optical recording and the dgn (red) is largest at the most posterior recording site (bottom). White rectangle represents the area where the eSIZ can be expected. n, Neuropil. Horizontal scale bar, $150 \mu \mathrm{m}$. Vertical scale bars, $0.1 \%$ fluorescence change. D, Time difference between optical and $d g n$ recordings as a function of the imaging position along the stn for three preparations. The delay increases toward position 0 (anterior end of the STG neuropil) showing that AGR's eSIZ lies either close to the STG neuropil or within it. 
and provides a good signal-to-noise ratio for optical recordings in STG neurons (Städele et al., 2012; Preuss and Stein, 2013). Several imaging sessions were recorded at each location, resulting in 200400 APs that were then averaged. We initially analyzed the change in fluorescence for individual axons in the most ventral layer of the axon bundle (Fig. 3Biiii). In all cases, exactly one axon showed a peak in fluorescence that was time-locked to the AGR AP on the extracellular recording (Fig. 3Bi, axon 1). Our analysis revealed that the signal-to-noise ratio after averaging $>100$ APs was high enough to detect the AGR AP even when multiple axons were selected simultaneously. This allowed us to use a rectangular ROI (Fig. $3 B b$, box). The average change in fluorescence was slightly decreased in amplitude and broadened compared with individual axons, but distinct enough to detect the AGR AP. Thus, this method appears to be sensitive enough to detect APs of individual neurons in a nerve containing $>50$ axons (Coleman et al., 1992) without knowing the exact location of a particular object of interest. By moving the objective (and consequently the ROI) along the stn in posterior direction (toward the STG, $\sim 330 \mu \mathrm{m}$ step size), we were able to track the AGR AP in 3 of 5 preparations. In 2 preparations, the signal-to-noise ratio of the optical signal was not sufficient to detect the AGR AP at all locations of the stn. When comparing the time difference between AP occurrence on the optical recording and the extracellular $d g n$ recording, the longest time difference between the optical and the extracellular recording site reveals the site of spike initiation. This is the case because ectopic APs travel orthodromically and antidromically starting at the site of initiation. For example, the time difference between the optical and extracellular recordings would be very small if the two recording sites were approximately at the same distance from the initiation site, but on opposite sides of it. Our approach does not require orthodromic and antidromic spikes to travel at the same velocity. The time difference between recordings gets longer as the optical recording is moved toward the initiation zone, and it is longest when the optical signal is measured at the spike initiation site itself (because the AP is immediately detected on the optical recording, but still has to travel all the way to the extracellular $d g n$ recording). We found that the AP latency between the optical recording and the $d g n$ recording continuously increased from anterior optical recording sites to more posterior recording sites (i.e., when the objective was moved closer to the posterior part of the stn) (Fig. 3C). Across preparations, the AP latency was highest near the anterior end of the STG (Fig. 3D), indicating that spontaneous ectopic spiking was initiated nearby. Optical recordings were not continued further posteriorly as the AGR axon enters the STG neuropil and
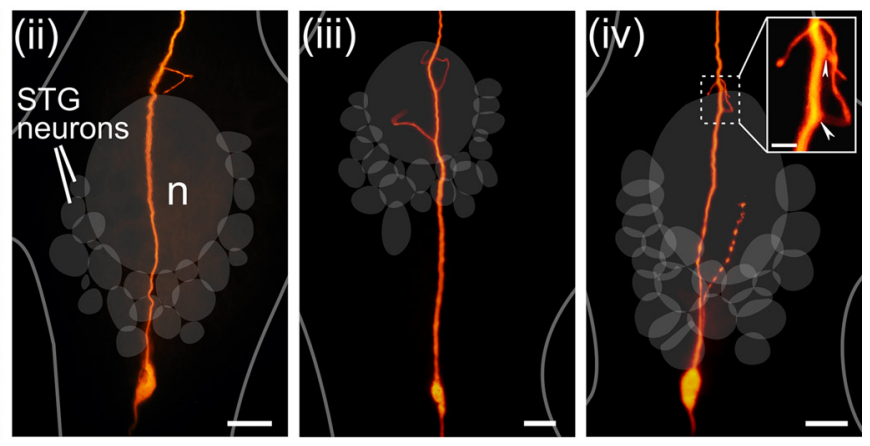

B

C

D
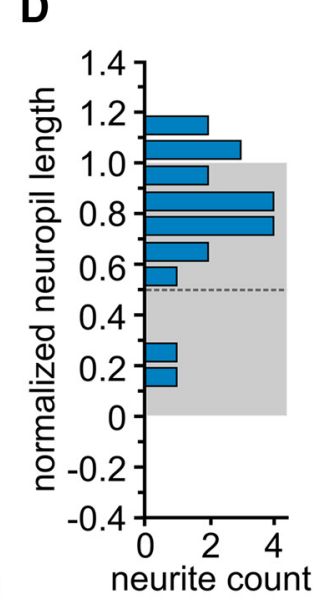

STG neuropil

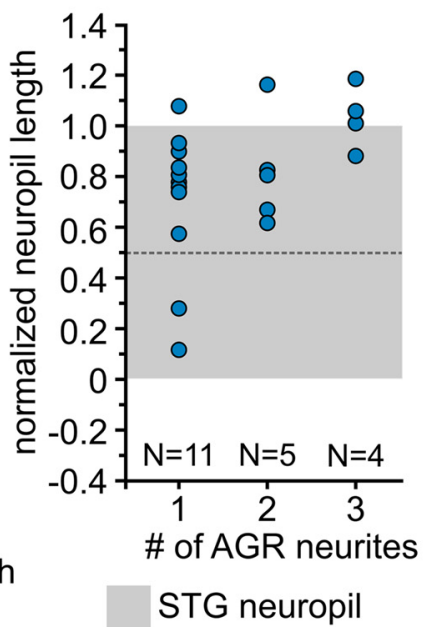

neurite count

Figure 4. The AGR axon possesses neurites in the anterior STG neuropil. $A$, Example stainings of four AGR somata and axons. AGR axons either possessed one (Ai,ii), two (Aiii), or three neurites (Aiv) that projected into the STG neuropil. $\boldsymbol{A i}$, Double staining Inset, Two neurites leaving the AGR axon in higher magnification. Scale bars: $100 \mu \mathrm{m}$; inset, $20 \mu \mathrm{m}$. $\mathrm{n}$, Neuropil. $\boldsymbol{B}_{\boldsymbol{\prime}}$ (he STG. Blue circles represent the positions where neurites originated a 作 , the most anterior neurite in the STG neuropil. Bin size: 0.1 normalized neuropil length. Of the 20 AGR axons shown, only two had neurites in the lower half of the neuropil.

long-term illumination of the STG neuropil with this dye has been shown to change neural activity and to cause permanent phototoxic damage (Stein and Andras, 2010; Preuss and Stein, 2013). Illumination of the $s t n$, in contrast, did not change the AGR firing frequency or the activity of the STG circuits in any of our experiments. Likewise, the latency between the $d g n$ and a second extracellular recording site (the son) remained unchanged independently of which part of the stn was illuminated. Thus, application of Di-4-ANEPPS and illumination of the axonal membrane affected neither the eSIZ nor its spike frequency.

The spatial resolution of optical imaging is not determined by the field of view, but rather by the temporal resolution of the camera and how far APs travel during each camera frame. To assess the spatial acuity of our experiments, we calculated the conduction velocity of the AGR axon in the stn. On average, we found that spikes propagated with an average conduction velocity of $0.90 \pm 0.11 \mathrm{~m} / \mathrm{s}(N=24)$. At this speed, APs travel $\sim 1.2$ 
$\mathrm{mm}$ per frame (at $1.3 \mathrm{~ms}$ per frame), which is three times the field of view of the camera (field of view is $400 \mu \mathrm{m}$ at a magnification of $20 \times$ ). The average length of the $\sin$ from the anterior end of the STG neuropil to the $s t n / s o n$ junction was $12.5 \pm 2.7 \mathrm{~mm}(N=$ 16). The average distance between the AGR soma and the anterior end of the STG neuropil was $0.86 \pm 0.35 \mathrm{~mm}(N=13)$. Because AGR's ectopic APs were not generated in the soma (Fig. $1 C$ ), the eSIZ must have been located between the AGR soma and up to $1.17 \mathrm{~mm}$ away from the anterior border of the STG neuropil $(<10 \%$ of the length of the $s t n$; depicted in Fig. $3 C$, squared area), which confirms the results we obtained with light-induced activation of ectopic spiking (Fig. 2D).

\section{AGR's spontaneous eSIZ is located in close vicinity to axonal neurites}

The STG neuropil is an area of extensive synaptic communication, densely packed with dendrites and axons of pyloric and gastric mill motor and interneurons, as well as projection and sensory neurons (Kilman and Marder, 1996; Christie et al., 1997; Skiebe and Ganeshina, 2000; Bucher et al., 2007). The fact that ectopic spikes were consistently initiated in or near the neuropil could be due to a functional necessity, namely, allowing a "local" control of ectopic firing frequency. Goeritz et al. (2013) have shown that AGR possesses between 1 and 3 neurites that branch off the main axon in the STG neuropil and make putative synaptic contacts onto STG motor neurons. In particular, synaptic connections between AGR and the GM neurons have been suggested. However, all previous studies failed to provide evidence for synaptic input from the GMs or other STG neurons in intrasomatic AGR recordings, most likely because the STG was desheathed (Goldsmith et al., 2014). We hypothesized that ectopic spikes are initiated near the branch points of the AGR neurites, in close vicinity to putative synaptic inputs. To test this, we revisited the anatomy of the AGR axon by iontophoretically injecting fluorescent dyes into the AGR soma. As reported previously (Goeritz et al., 2013), we found that AGR possesses between 1 and 3 primary neurites leaving the central axon in the STG (Fig. $4 A$; average: $1.65 \pm 0.81$ neurites, 11 with 1 neurite, 5 with 2 neurites, and 4 with 3 neurites, $N=20$ ). Because detailed information about where in the neuropil these branches originate is not available, we determined the origin of the neurites by normalizing the length and width of the neuropil for comparison across animals (length: posterior border $=0$, anterior border $=$ 1 ; width: left $=0$, right $=1$; average length: $454.33 \pm 133.82 \mu \mathrm{m}$, width: $301.14 \pm 99.10 \mu \mathrm{m}, N=20$ ). In all cases, AGR had at least one primary neurite in the STG neuropil. Although the origins of these neurites were rather distributed within the neuropil (Fig. $4 B$ ), we found that in 18 of the 20 stained AGR neurons at least one neurite originated in the anterior half of the STG neuropil (Fig. 4C) where the eSIZ is located.

\section{AGR's ectopic spiking is influenced by STG motor neurons}

We have previously reported that AGR's ectopic firing frequency can be altered by gastric mill activity (Goldsmith et al., 2014). Specifically, AGR's frequency increases during the bursts of the lateral gastric protractor neuron and decreases during the lateral gastric interburst. This effect can only be observed when the STG remains undesheathed, a condition that impedes intracellular recordings from STG neurons. It is unknown whether this alteration of the AGR firing frequency occurs locally at the eSIZ and by which neurons it is mediated. Figure $5 \mathrm{~A}$ shows the change in AGR firing frequency when a long-lasting gastric mill rhythm was started by stimulation of the mechanosensory VCN pathway
(Beenhakker et al., 2004). Our analysis revealed that the AGR frequency increased consistently during the activity phase of the protractor motor neurons (such as the GM neurons; Fig. 5B; $N=$ 16). To test whether the alteration of AGR firing frequency occurred at the eSIZ, we measured the time delays of the AGR AP occurrence at the $s t n$ and $d g n$ recording sites before and during VCN stimulation. A shift in the SIZ during VCN stimulation should manifest itself in a shift of the relative timing between the two recordings. In none of our experiments this was the case (Fig. $5 C$ ), indicating that the alteration indeed occurred electrotonically close to the eSIZ.

We then tested whether the GM motor neurons contributed to the local influence because they were active in phase with the increase in AGR ectopic firing frequency and had previously been indicated to possess putative synapses with AGR (Goeritz et al., 2013). We retrogradely activated GM neurons with extracellular stimulation. Intracellular recordings were not feasible without desheathing the ganglion. As already mentioned, desheathing impedes the alteration of AGR's firing frequency (Goldsmith et al., 2014). There are four GM neurons in the STG of C. borealis, and they innervate their target structure (gastric mill muscles) via projections in several small side nerves leaving the $d g n$. These small nerves exclusively contain GM axons, typically two or three of them, which allowed us to activate multiple (but not all) GM neurons simultaneously. We used trains with 25 and $40 \mathrm{~Hz}$ stimulation frequency (see Materials and Methods). Figure $5 D$ shows an original recording of the $\sin$ (with AGR spikes) and $40 \mathrm{~Hz} \mathrm{GM}$ stimulation (top trace depicts the AGR firing frequency). Whenever the GM neurons were activated, AGR firing frequency increased, indicating that AGR's ectopic spiking is indeed affected by STG motor neuron activity. This increase occurred consistently and was significant only during the activity phase of the GM neurons (Fig. 5E; $N=8$ ). The increase was frequency dependent: $40 \mathrm{~Hz}$ GM stimulation elicited significantly larger responses for phases $0.1-0.4$ than $25 \mathrm{~Hz}$ stimulation. Although we cannot exclude contributions of other neurons, activating the GMs was sufficient to elicit an increase in AGR firing frequency.

Similar to the VCN stimulation, direct activation of the GM neurons had no effect on the relative timing of the AGR APs on the extracellular recordings (Fig. 5F). This indicated that the GMs affected AGR spike frequency by altering the spontaneous eSIZ in the neuropil.

\section{Potential functional relevance of small changes in AGR firing frequency}

We were curious whether small changes in AGR firing frequency are functionally important and able to affect postsynaptic target neurons. However, the consequences of AGR activity are difficult to study because AGR is part of a closed-loop system. AGR innervates several identified projection neurons in the paired commissural ganglia (Hedrich et al., 2009), including the commissural projection neuron 2 (CPN2) (Norris et al., 1994). These projection neurons activate the GM motor neurons in the STG, which in turn affect AGR firing (Fig. 5). We thus performed open-loop experiments in which we measured the effects of changes in AGR firing on projection neuron activity and the gastric mill motor circuit. In the first case, we performed simultaneous intracellular recordings of projection neurons and AGR somata without ongoing gastric mill activity (i.e., open loop). For the analysis, we focused on CPN2 because its effects on the STG motor circuits are well characterized (Norris et al., 1994). Without sensory stimulation or spontaneous gastric mill activity, CPN2 is typically active at very low firing frequencies (Beenhakker and Nusbaum, 

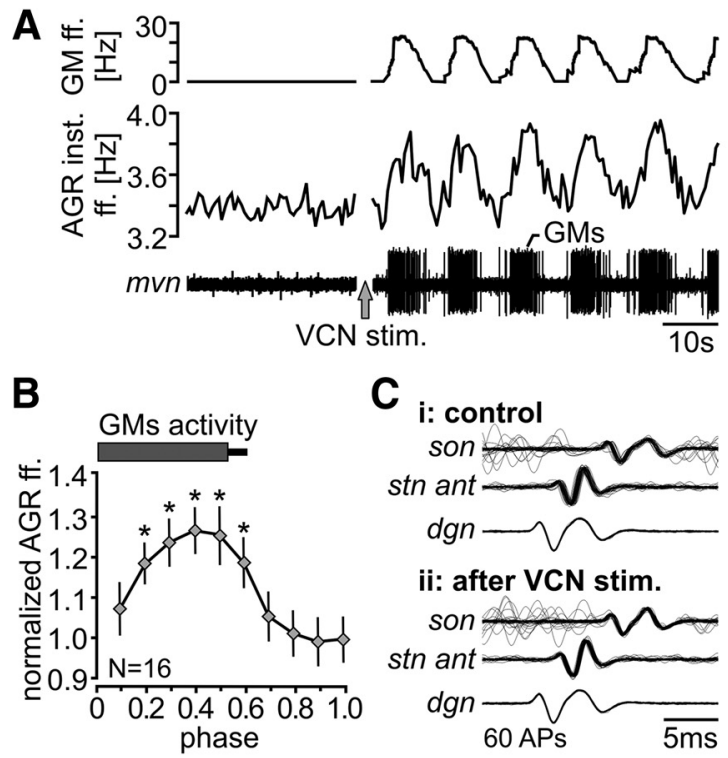

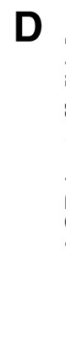

E

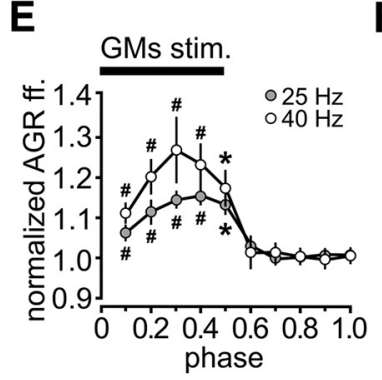

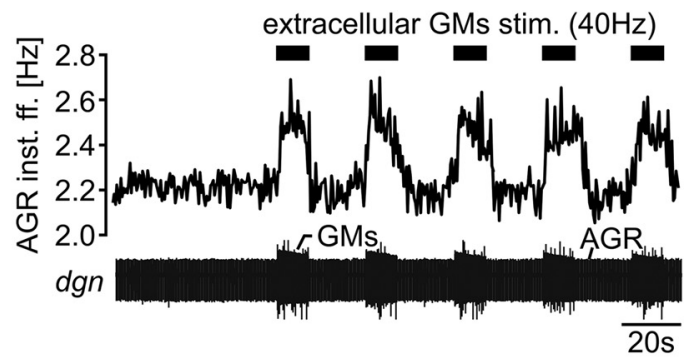

$\mathbf{F}$

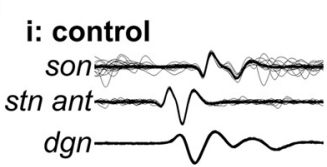

ii: during GMs stim.

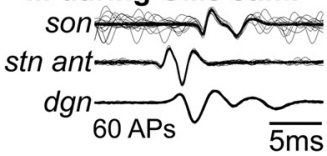

Figure 5. GM neurons alter AGR's spontaneous ectopic firing. $A-C$, Extracellular VCN stimulation. $D-F$, extracellular GM stimulation. $A$, AGR inst. ff. and GM neurons firing frequency before and 5 min after VCN stimulation (arrow), plus extracellular recording of the mvn showing GM neuron activity. After VCN stimulation, AGR inst. ff. increased rhythmically in time with GM bursts. $\boldsymbol{B}$, Phase analysis of rhythmic AGR inst. ff. changes for 16 animals after VCN stimulation. The activity of the GM neurons is shown at the top (mean \pm SD). AGR inst. ff. was normalized and binned (bin size: Phase 0.1 , bottom). AGR firing frequency of phases $0.2-0.6$ (during GM bursts) was significantly increased compared with phases $0.7-1.0$ (during GM interburst; one-way repeated measures ANOVA, $p<0.001, F_{(9,135)}=53.001$, Holm-Sidak post hoc test with $\left.p<0.05, N=16\right)$. C, Comparison of spike delays between dgn, stn anterior, and son before (top) and after VCN stimulation (bottom). Overlay of $60 \mathrm{APs}$. Delays did not change showing that VCN stimulation did not affect the location of the eSIZ. Despite the fact that in this particular example APs occurred $\sim 2 \mathrm{~ms}$ earlier on the dgn recording, APs were initiated in between the dgn and stn anterior recordings (i.e., near the STG neuropil). D, AGR inst. ff. before and during rhythmic extracellular GM stimulation (top), plus extracellular recording of the dgn (bottom), showing the response of the GM neurons. AGR inst. ff. increased transiently during repetitive GM stimulation (black bars). $E$, Phase analysis of AGR inst. ff. changes in response to $\mathrm{GM}$ stimulation with $40 \mathrm{~Hz}(N=8)$ and $25 \mathrm{~Hz}(N=4)$. For both stimulation frequencies, AGR firing frequency of phases $0.1-0.5$ (during $\mathrm{GM}$ stimulation) was significantly increased compared with phases $0.6-1.0$ (no GM stimulation; one-way repeated measures ANOVA, $p<0.001$, Holm-Sidak post hoc test with $p<0.05 ; 40 \mathrm{~Hz}: F_{(9,63)}=67.151, \mathrm{~N}=$ $8 ; 25 \mathrm{~Hz}: F_{(9,27)}=40.508, \mathrm{~N}=4$ ). Pound signs represent additional significant differences between 25 and $40 \mathrm{~Hz} \mathrm{GM}$ stimulation (phases $0.1-0.4 ; p<0.05$, paired $t$ test for each phase). $\boldsymbol{F}$, There was no change in spike delays between dgn, stn anterior, and son before and during GM stimulation.

2004; Beenhakker et al., 2004). We found that small changes in AGR firing frequency caused an increase in CPN2 spike activity. In the experiment shown in Figure 6A, we injected a slow depolarizing DC current ramp into the AGR soma to alter AGR spike activity. An increase in AGR frequency of $<1 \mathrm{~Hz}$ caused a concomitant increase in CPN2 activity. To further scrutinize the influence of AGR on CPN2, we modified AGR firing frequency via intracellular current pulse injections, ranging from 1 to $5 \mathrm{~Hz}$ in 1 $\mathrm{Hz}$ steps. Each frequency was maintained for at least $30 \mathrm{~s}$, and frequency levels were applied in random order. Figure $6 B$ shows that the mean CPN2 spike activity determined over $30 \mathrm{~s}$ increased significantly with AGR firing frequency.

Finally, we tested whether small changes in AGR firing frequency influenced the downstream motor circuits in the STG. For this, we elicited a gastric mill rhythm via VCN stimulation and again altered AGR frequency in $1 \mathrm{~Hz}$ steps. We averaged the cycle period of 10 consecutive cycles of the gastric mill rhythm at each AGR frequency to describe changes in motor output. We found a significant increase in cycle period with AGR firing frequency (Fig. 6C). Between AGR firing frequencies of $2-4 \mathrm{~Hz}$, cycle period increased at a rate of $9 \% / \mathrm{Hz}$. Together, our data indicate that even small changes in AGR frequency impact postsynaptic projection neurons and motor circuits, supporting the idea that the changes in AGR frequency elicited by GMs/VCN stimulation are functionally relevant.

\section{The location of spike initiation is important for} signal integration

Our data indicate that the location of the eSIZ facilitates signal integration and allows the rhythmic alteration of the ectopic AGR firing frequency in vitro. Consequently, a dislocation of the eSIZ should abolish signal integration. We tested this hypothesis by reducing axon excitability in the stn with application of $\mathrm{HiDi}$ exclusively to the eSIZ (see Material and Methods). It has previously been described that HiDi raises spike threshold, inactivates AGR's eSIZ, and causes a secondary and more distant eSIZ to become active (Daur et al., 2009). Figure $7 A$ shows an experiment in which HiDi was bath-applied to the eSIZ in the stn. AGR firing frequency dropped in response to HiDi application, causing the site of spike initiation to change and spikes to be generated more posteriorly in the $d g n$ (Fig. $7 B$ ). This was the case in six of nine experiments (Fig. 7C). In the remaining three experiments, spiking in AGR was suppressed and no secondary eSIZ was activated. To test whether dislocating the eSIZ affected the rhythmic alteration of AGR's firing frequency, we elicited a gastric mill rhythm in HiDi via VCN stimulation. Here, we used VCN stimulation rather than direct stimulation of the GM neurons to prevent an accidental direct activation of the eSIZ in the $d g n$ (as GM stimulation was performed by stimulating a side branch of the $d g n)$. Figure $7 D$ shows AGR's ectopic spike activity after VCN stimulation in normal saline (top) and when the stn was bathed in HiDi (bottom). In saline, AGR's firing frequency increased during every GM neuron burst. In contrast, after a shift of the eSIZ to the $d g n$ in HiDi, rhythmic alteration of AGR firing frequency was absent. This was consistent for all preparations tested (Fig. 7E).

In many neuron types, ectopic spiking can be elicited in response to neuromodulator application (for review, see Pinault, 1995; Bucher and Goaillard, 2011). There are several examples for such neuromodulator actions in the stomatogastric nervous sys- 

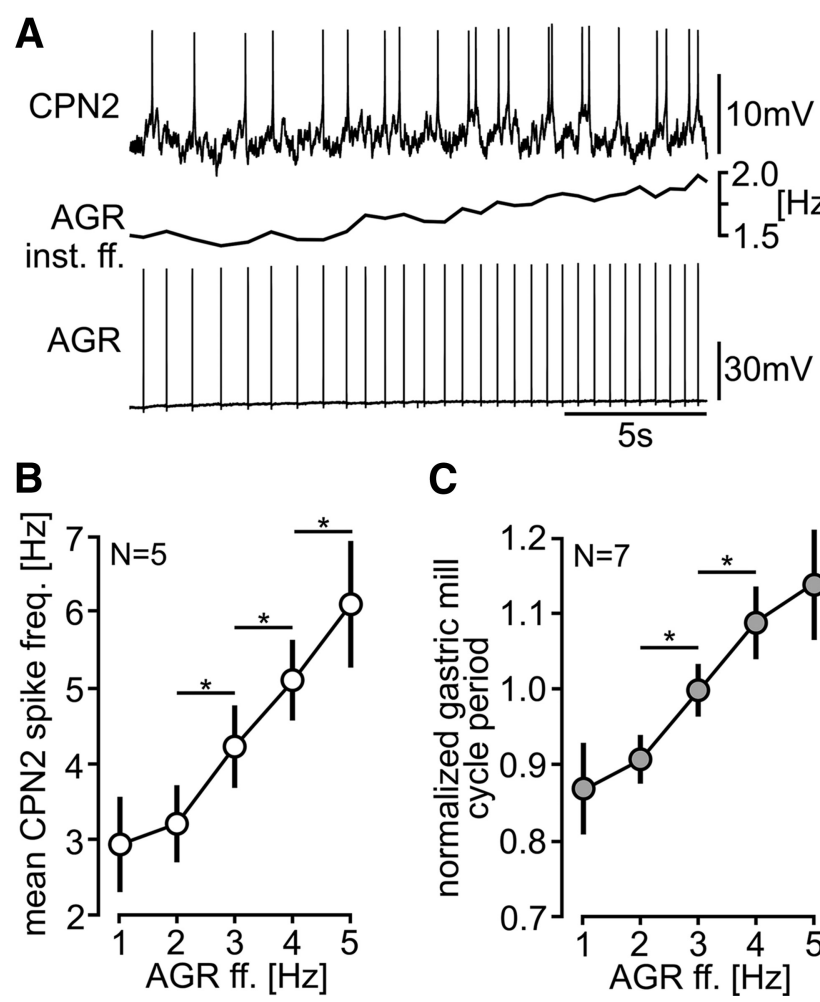
2.0

Figure 6. Changes in AGR firing frequency affect postsynaptic neurons and circuits. $A$, Intracellular recordings of CPN2 (top) and AGR (bottom). An increase in AGR inst. ff. (middle trace) of $\sim 0.5 \mathrm{~Hz}$ led to a concomitant increase in CPN2 activity. B. Across animals, mean CPN2 spike frequency increased significantly with higher AGR inst. ff. (one-way repeated measures ANOVA, $p<0.001, F_{(4,16)}=32.840$, Holm-Sidak post hoc test with $\left.p<0.05, N=5\right)$. The pairwise comparison revealed significant differences between $2,3,4$, and $5 \mathrm{~Hz}$, respectively. Mean CPN2 activity was determined by averaging epochs of $30 \mathrm{~s}$ at each AGR frequency. C, Analysis of the change in gastric mill cycle period during stepwise (randomized) AGR firing frequency changes. Ten consecutive gastric mill cycles in each animal were normalized to the mean cycle period (one-way repeated measures ANOVA, $p<0.001, F_{(4,24)}=26.860$, Holm-Sidak post hoc test with $p<0.05, N=7$ animals). The pairwise comparison revealed significant differences between 2,3 , and $4 \mathrm{~Hz}$, respectively.

tem (Meyrand et al., 1992; Combes et al., 1997; Bucher et al., 2003; Goaillard et al., 2004), where eSIZs are activated in the axon trunk. The functional consequences of the elicited ectopic APs are often discussed with reference to their effects on the postsynaptic targets. We hypothesized that eliciting ectopic spiking by neuromodulation may also dislocate the SIZ to dynamically adjust signal integration.

The AGR axon projects through an area of a few hundred micrometers that has previously been suggested to be a target for neuromodulators, and in particular for OA, which elicits local ectopic spiking in the axon of a projection neuron (Goaillard et al., 2004). This area is located in the anterior $\operatorname{stn}$ (close to the $s t n /$ son junction) and can be easily recognized because of its wider diameter (Fig. 1A). Extrinsic application of OA increases AGR's tonic firing frequency (Daur et al., 2009), although it is unclear how OA modulation affects the eSIZ. We applied OA $(50 \mu \mathrm{M}$, similar to Goaillard et al., 2004; Daur et al., 2009) to the anterior $s t n$. AGR spike activity was monitored extracellularly on the dgn, on three sites along the $\operatorname{stn}$ (posterior, middle, and anterior), and on the son. We found that AGR's tonic spike frequency increased during OA application (Fig. $8 \mathrm{~A}$ ), indicating that OA increases the excitability of the axon membrane at the application site. The minimum effective concentration was $10 \mu \mathrm{M}$ (saline: $3.52 \pm 0.52 \mathrm{~Hz}$; OA $1 \mu \mathrm{M}$ : $3.89 \pm 0.65 \mathrm{~Hz}, p=0.28$; OA

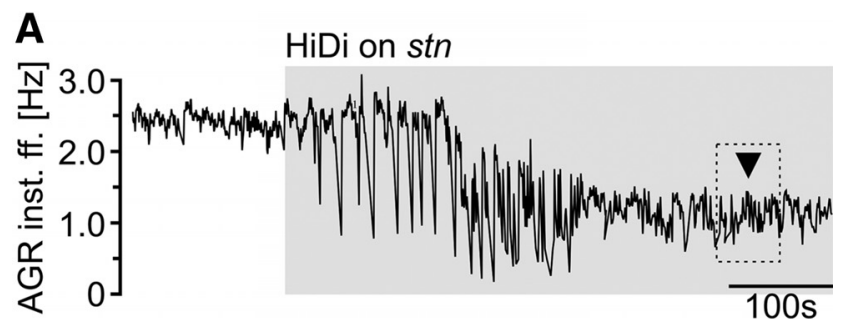

B
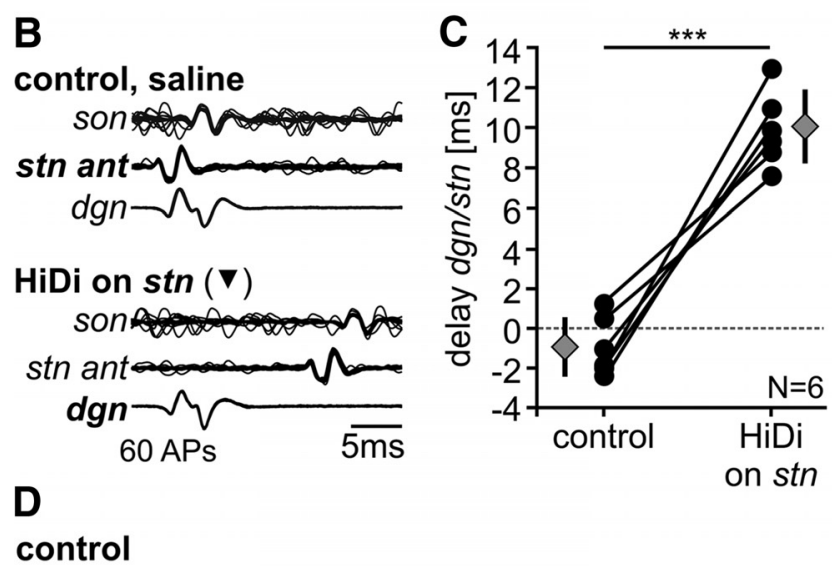

control
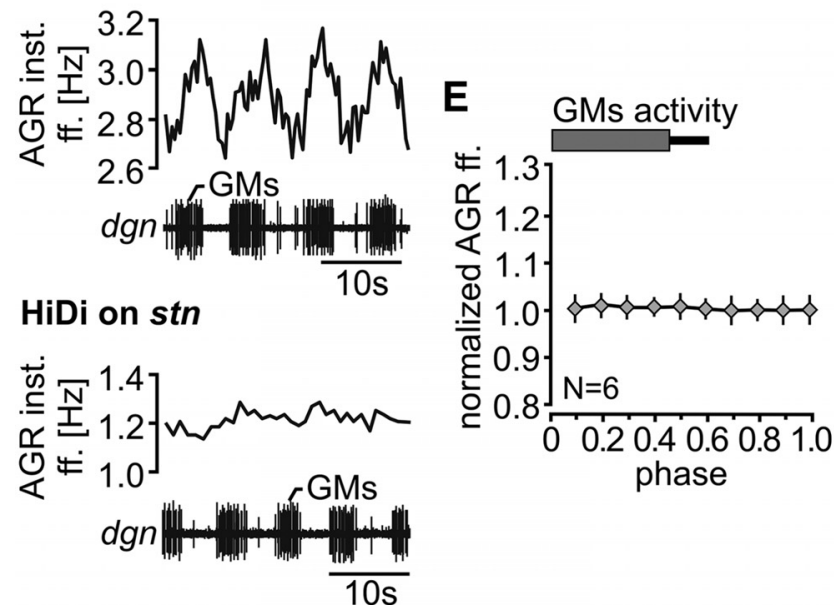

Figure 7. Shifting AGR's spontaneous eSIZ prevents signal integration. $\boldsymbol{A}$, Change in AGR inst. ff. after HiDi saline application to the stn (gray bar). Rectangle represents the area used for conduction delay analysis in $\boldsymbol{B}$. $\boldsymbol{B}$, Average ( $60 \mathrm{APs}$ ) change in conduction delay between dgn, stn anterior, and son before (top) and after HiDi application (bottom). In saline (control), APs occurred first on the stn anterior recording (indicated in bold), whereas in HiDi APs were generated in the dgn. $\boldsymbol{C}$, Conduction delays between dgn and stn anterior before and during HiDi application for all experiments $(N=6)$. Positive values indicate that the spike first appeared on the dgn. Across animals, there was a significant shift of AGR's eSIZ toward the dgn ( $p<0.001$ paired $t$ test, $N=6) . D, A G R$ inst. ff. after VCN stimulation in control condition (saline, top) and during HiDi saline application to the stn (bottom). The extracellular recording of a dgn side branch shows the activity of the GM neurons. In HiDi, no rhythmic alteration of the AGR inst. ff. was present despite the fact that the GM neurons were rhythmically active. $\boldsymbol{E}$, Phase analysis of AGR's inst. ff. in response to VCN stimulation in HiDifor 6 preparations. No significant differences were found ( $p=0.23$, one-way repeated measures ANOVA, $\left.F_{(9,45)}=2.84, N=6\right)$.

$10 \mu \mathrm{M}: 5.48 \pm 1.23 \mathrm{~Hz}, p<0.001$; OA $50 \mu \mathrm{M}: 5.74 \pm 0.91 \mathrm{~Hz}$; $p<0.001$, repeated-measures ANOVA, $F_{(3,15)}=21.46$, HolmSidak post hoc test, $N=6$ ). The increase in firing frequency was always accompanied by a shift in the eSIZ toward the application site. Figure $8 B$ shows the AGR spike occurrence at the different recording sites during OA application. When OA was applied to the anterior stn, APs appeared first at the anterior stn and then propagated toward the other axonal sections. 
In all preparations tested, application of OA to the anterior stn consistently relocated the eSIZ from the neuropil toward the anterior part of the $s t n$, as indicated by the significant decrease in AP delay between the $d g n$ and $s t n$ in OA (Fig. $8 C$; $N=11$ ). This effect was reversible (i.e., after OA washout spikes were again initiated at the primary eSIZ).

To test whether this modulatorinduced dislocation indeed abolished signal integration in the axon, we stimulated the $\mathrm{VCN}$ in $\mathrm{OA}$ and monitored the AGR ectopic firing frequency. Figure $8 D$ shows that rhythmic alteration of the AGR firing frequency was absent after shifting the eSIZ with OA, precluding signal integration. This was consistent for all preparations tested (Fig. $8 E ; N=4$ ).

It is possible that, instead of the dislocation, the increase in AGR firing frequency, as observed during OA application, occluded the influence of the GM neurons, for example, by bringing AGR frequency to its upper limit. To exclude this possibility, we additionally applied OA to the whole stn, including the primary eSIZ in the neuropil. This increased AGR firing frequency (saline: $2.8 \pm 0.5$ $\mathrm{Hz}, \mathrm{OA}: 4.8 \pm 0.3 \mathrm{~Hz} ; p<0.001$, paired $t$ test, $N=6$ ) but did not relocate the SIZ to the anterior $\operatorname{stn}$ (Fig. $8 F$ ). When we then elicited a gastric mill rhythm with $\mathrm{VCN}$ stimulation, rhythmic alteration of the AGR frequency was still present (Fig. 8G), indicating that the observed increase in AGR firing frequency did not occlude the effects of the GM neurons on the AGR axon. The fact that global OA application did not cause a shift in the eSIZ indicates that axonal excitability was globally and rather uniformly increased. This contrasts to the application of OA at a distant axon region that causes a local increase in excitability and concomitantly a dislocation of the SIZ. Together, our results thus indicate that a shift of the eSIZ away from the neuropil region precludes signal integration.

\section{Discussion}

Recent studies have suggested that size and location of SIZs are involved in regulating neuron excitability and in defining responses to synaptic inputs and membrane potential changes (Kuba et al., 2006, 2010; Grubb and Burrone, 2010). Although fine-tuning neuronal responses via modification of the location where spikes are initiated is an elegant mechanism to increase neuronal flexibility, so far only slow homeostatic adaptations have been demonstrated (Grubb and Burrone, 2010; Kuba et al., 2010). Here we present a dynamic mechanism to increase the flexibility repertoire of neural networks via a rapid shift in the site of spike initiation. Using ectopic AP generation in the single-cell muscle-tendon organ AGR, we show that axonal neuromodula-
B

\section{OA $(50 \mu \mathrm{M})$ on stn anterior}

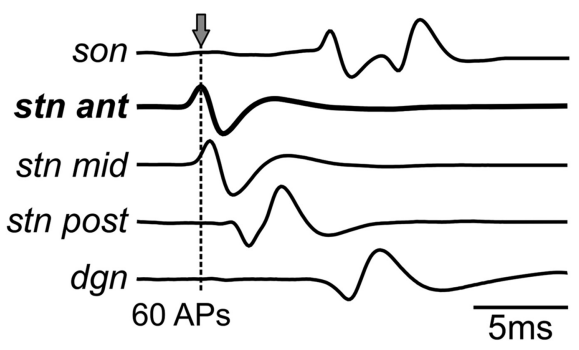

F

\section{AA $(50 \mu \mathrm{M})$ on whole stn}

Figure 8. OA causes a switch of the eSIZ that prevents signal integration. $A$, AGR inst. ff. in response to OA application (gray bar). 0 A was applied into a petroleum-jelly well at the stn anterior. $B$, Averages ( $60 \mathrm{APs}$ each) of the AGR spike activity showing the spike occurrence at 5 extracellular recording sites along the AGR axon. The site of $O A$ application is indicated in bold. APs occurred first on the stn anterior. C, Average conduction delays between dgn and stn anterior before and during $0 \mathrm{~A}$ application to the stn anterior for shift of AGR's eSIZ toward the site of OA application $(p<0.001$, paired $t$ test, $N=11)$. D, AGR inst. ff. and original recording of the $n$ after VCN stimulation during $0 \mathrm{~A}$ application to the stn anterior. After dislocating AGR's eSIZ to the stn anterior with OA AGR ff. in response to VCN stimulation during $0 \mathrm{~A}$ application to the stn anterior for 4 experiments. No significant differences were ( $p=0.16$, one-way repeated measures ANOVA, $\left.F_{(9,27)}=2.843, N=4\right) . F$, Averages ( 60 APs each) of AGR spike occurrence irst at the stn posterior. G, Phase analysis of AGR inst. ff. in response to VCN stimulation when OA was applied to the whole stn. AGR ff. of phases $0.1-0.6$ (during GM bursts) was significantly increased compared with phases $0.7-1.0$ (during GM interburst; one-way repeated measures ANOVA, $p<0.001, F_{(9,27)}=39.641$, Holm-Sidak post hoc test with $\left.p<0.05, N=4\right)$. tion shifts the location of spike initiation away from the primary zone. This shift has functional consequences in that it prevents signal integration from synaptic partners. Furthermore, the ability of the GM motor neurons to change AGR's ectopic firing rate represents a local interaction between sensory and motor systems at an early stage of sensory processing.

Ectopic spike initiation, local feedback, and neuromodulation AGR has been identified in the STG of several crustacean species (Combes et al., 1993; Combes et al., 1995). In the crab, C. borealis, AGR is a bipolar neuron with a several-centimeterslong peripheral axon that innervates protractor muscles. Orthodromic AGR APs are generated near the innervated 
muscles and propagate actively toward the AGR soma, which is located in the STG. APs continue through the active soma and along the several-centimeters-long central axon to upstream projection neurons in the commissural ganglia.

AGR is part of a sensory feedback loop that controls the gastric mill rhythm (Daur et al., 2009). The same projection neurons in the commissural ganglia, which receive input from AGR (Hedrich et al., 2009), activate the GM motor neurons, which then evoke contractions of the gastric mill powerstroke muscles. Changes in tension of the muscles innervated by AGR in turn influence AGR firing. However, AGR is not always peripherally activated during muscle contractions: only when muscle tension exceeds a certain threshold are spikes initiated in the periphery (Smarandache et al., 2008). To our knowledge, our study is the first to demonstrate that intermediary to this long-loop feedback, local interactions between sensory axons and motor systems exist. The GMs alter the spike activity AGR generates at the eSIZ in the STG neuropil (Fig. 5). As the final stage of neural processing, motor neurons convey the ultimate motor programs for the execution of behaviors to the muscles. We found an unforeseen role of motor neurons, namely, the regulation of spike initiation in a sensory neuron. Motor neurons are thus not just passive recipients of motor commands. Rather, they appear to be an integral component of adjusting motor output by influencing sensory axons. Although not discovered in other systems yet, it is conceivable that such interactions are also present in other animals.

With regard to regulating AGR firing, axonal neuromodulation provides an interesting functionality. OA can shift the site of spike initiation away from the site of sensorimotor interaction (Fig. 8). When this happens, local influences exerted by the motor neurons are abolished. Axonal modulation by neuromodulators might thus represent a convenient way of mediating statedependent interactions between sensory and motor systems in that some modulatory conditions enable local feedback and others disable it. Neuromodulators are well known to elicit statedependent actions (for review, see Stein, 2009; Brezina, 2010; Harris-Warrick, 2011; Lee and Dan, 2012) and gating of neuronal information has been shown in several systems. For example, in Aplysia, spike propagation in the sensory neuron B21 is gated by soma membrane potential (Evans et al., 2003). In cortex, there are indications that microdomains can be established by neuromodulation in subcellular compartments, such as dendritic spines (Lur and Higley, 2015). Similarly, at the output side of neurons, APs can be shunted by presynaptic inhibition on the sensory terminals, effectively gating signal transmission (Stein and Schmitz, 1999; Cattaert et al., 2001; Barrière et al., 2008; McGann, 2013; Fink et al., 2014). To our knowledge, our study is the first to show that motor neurons influence ectopic spiking in the axon trunk and that a modulator-induced dislocation of the site of spike initiation alters this signal processing. In the case of AGR, the alteration of ectopic spiking via GM neurons represents an early point of interaction between the sensory and motor system, far away from dendritic input and output structures. This interaction can be gated by OA application at a distal site of the axon. Our results indicate that the whole AGR axon in the $\operatorname{stn}$ is endowed with OA receptors. However, it remains unclear whether OA is locally released or present as a circulating hormone. Minimally, our results present a proof of principle that dislocation of the site of AP initiation via neuromodulation can gate signal integration in axons. Because many axons are endowed with ionotropic and metabotropic receptors for transmitters and neuromodulators that are nonuniformly distributed along the axon trunk (Swadlow et al., 1980;
Lorincz and Nusser, 2008; Vacher et al., 2008; Nusser, 2009; Luján, 2010), it is conceivable that dislocation of the site of AP initiation via axonal neuromodulation represents an understudied mechanism for plasticity.

\section{Motor neuron influence on AGR ectopic spiking}

Goeritz et al. (2013) showed that AGR neurites contain putative chemical synapses and that the GM motor neurons are potential synaptic partners of AGR. The GM neurons are part of the gastric mill motor circuit that drives mastication of food. We found that spontaneous ectopic spike initiation in AGR is influenced by the GM neurons (Fig. 5D-F). GM activation increased AGR's firing frequency without affecting the location of the eSIZ. Whether this effect is mediated chemically or electrically is not clear. Although the GM neurons excite the gastric mill muscles via acetylcholine (Marder, 1976), it appears that they only interact via gap junctions within the STG (Nusbaum and Beenhakker, 2002). Fast synaptic actions on AGR seem unlikely, however, because of the rather slow changes in AGR firing frequency. Rather, slow metabotropic actions or weak electrical connections may elicit the observed interaction. In any case, alteration of ectopic spikes requires that the input can be integrated and is electrotonically close to the site of spike initiation. This is reflected in the finding that the GM-induced increase in AGR firing frequency could only be observed when the eSIZ in the neuropil was active (Figs. $7 E, 8 E$ ). We used antidromic stimulation to activate the GMs. Antidromic activation of neurons in this system, however, does not always replicate the synaptic actions resulting from their orthodromic activation (Mulloney and Selverston, 1972). This is because APs only passively invade the STG neuropil, making neurotransmitter release a function of the baseline membrane potential. Because the GM neurons were at rest in our experiments, our results may underestimate the comparable effects occurring during the actual motor rhythm, when the GMs are bursting due to their depolarized membrane potential during a gastric mill rhythm.

Spontaneous spike initiation always occurred within \pm 250 $\mu \mathrm{m}$ of the anterior border of the STG neuropil (Fig. 2). AGR's axon trunk possesses at least one neurite in this area (Fig. 4). The diameter of the neurites is small compared with the main axon trunk. Morphological inhomogeneities, such as branch points, and rapid changes in axon diameter cause impedance mismatches that affect the current flow and conduction velocity (for review, see Bucher and Goaillard, 2011). Specifically, a decrease in diameter results in reduced capacitance and lower rheobase. Hence, morphological inhomogeneities, such as axon ramifications, cause local excitability changes with the result that AP generation at or in close vicinity to neurites is favored. Similarly, heightened excitability may favor alteration of ectopic spiking by synaptic input. Naturally, there may be additional factors influencing axonal excitability at the spike initiation site, such as the density and repertoire of voltage-gated channels.

\section{Axon modulation by $\mathrm{OA}$}

OA modulates many physiological processes in invertebrates (Roeder, 1999), including STG motor patterns (Flamm and Harris-Warrick, 1986). It is present in the stn (Barker et al., 1979), albeit in a different species (Panulirus interruptus). Goaillard et al. (2004) demonstrated that local application of OA to the anterior part of the $s t n$ activates ectopic spiking in a descending projection neuron (MCN5). This part of the $\operatorname{stn}$ contains synaptic structures with dense core vesicles (Kilman and Marder, 1996), indicative of neuronal modulator release at this site. We found that the AGR 
axon was also sensitive to OA in this part of the $s t n$, with similar sensitivities as described for MCN5 (micromolar range). Local OA application to the anterior stn excited the AGR axon, effectively inactivating the initiation zone at the STG and shifting it toward the application site (Fig. $8 B$ ). However, we also found that, when applied globally to the $s t n$, OA excited the primary eSIZ near the STG, increasing its spike frequency, but maintaining the influence of the motor neurons (Fig. 8G). Thus, global versus local modulation of an axon may allow for a dynamic adjustment of signal integration.

\section{References}

Barker DL, Kushner PD, Hooper NK (1979) Synthesis of dopamine and octopamine in the crustacean stomatogastric nervous system. Brain Res 161:99-113. CrossRef Medline

Barrière G, Simmers J, Combes D (2008) Multiple mechanisms for integrating proprioceptive inputs that converge on the same motor patterngenerating network. J Neurosci 28:8810-8820. CrossRef Medline

Beenhakker MP, Nusbaum MP (2004) Mechanosensory activation of a motor circuit by coactivation of two projection neurons. J Neurosci 24: 6741-6750. CrossRef Medline

Beenhakker MP, Blitz DM, Nusbaum MP (2004) Long-lasting activation of rhythmic neuronal activity by a novel mechanosensory system in the crustacean stomatogastric nervous system. J Neurophysiol 91:78-91. CrossRef Medline

Blitz DM, Nusbaum MP (1999) Distinct functions for cotransmitters mediating motor pattern selection. J Neurosci 19:6774-6783. Medline

Bostock H, Bergmans J (1994) Post-tetanic excitability changes and ectopic discharges in a human motor axon. Brain 117:913-928. CrossRef Medline

Brezina V (2010) Beyond the wiring diagram: signalling through complex neuromodulator networks. Philos Trans R Soc Lond B Biol Sci 365: 2363-2374. CrossRef Medline

Bucher D, Goaillard JM (2011) Beyond faithful conduction: short-term dynamics, neuromodulation, and long-term regulation of spike propagation in the axon. Prog Neurobiol 94:307-346. CrossRef Medline

Bucher D, Thirumalai V, Marder E (2003) Axonal dopamine receptors activate peripheral spike initiation in a stomatogastric motor neuron. J Neurosci 23:6866-6875. Medline

Bucher D, Johnson CD, Marder E (2007) Neuronal morphology and neuropil structure in the stomatogastric ganglion of the lobster, Homarus americanus. J Comp Neurol 501:185-205. CrossRef Medline

Calabrese RL (1980) Control of multiple impulse-initiation sites in a leech interneuron. J Neurophysiol 44:878-896. Medline

Carr CE, Boudreau RE (1996) Development of the time coding pathways in the auditory brainstem of the barn owl. J Comp Neurol 373:467-483. CrossRef Medline

Cattaert D, Libersat F, El Manira AA (2001) Presynaptic inhibition and antidromic spikes in primary afferents of the crayfish: a computational and experimental analysis. J Neurosci 21:1007-1021. Medline

Christie AE, Baldwin DH, Marder E, Graubard K (1997) Organization of the stomatogastric neuropil of the crab, Cancer borealis, as revealed by modulator immunocytochemistry. Cell Tissue Res 288:135-148. CrossRef Medline

Colbert CM, Pan E (2002) Ion channel properties underlying axonal action potential initiation in pyramidal neurons. Nat Neurosci 5:533-538. CrossRef Medline

Coleman MJ, Nusbaum MP, Cournil I, Claiborne BJ (1992) Distribution of modulatory inputs to the stomatogastric ganglion of the crab, Cancer borealis. J Comp Neurol 325:581-594. CrossRef Medline

Combes D, Simmers J, Nonnotte L, Moulins M (1993) Tetrodotoxinsensitive dendritic spiking and control of axonal firing in a lobster mechanoreceptor neurone. J Physiol 460:581-602. CrossRef Medline

Combes D, Simmers J, Moulins M (1995) Structural and functional characterization of a muscle tendon proprioceptor in lobster. J Comp Neurol 363:221-234. CrossRef Medline

Combes D, Simmers J, Moulins M (1997) Conditional dendritic oscillators in a lobster mechanoreceptor neurone. J Physiol 499:161-177.

Daur N, Nadim F, Stein W (2009) Regulation of motor patterns by the central spike-initiation zone of a sensory neuron. Eur J Neurosci 30: 808-822. CrossRef Medline

Evans CG, Jing J, Rosen SC, Cropper EC (2003) Regulation of spike initia- tion and propagation in an Aplysia sensory neuron: gating-in via central depolarization. J Neurosci 23:2920-2931. Medline

Fink AJ, Croce KR, Huang ZJ, Abbott LF, Jessell TM, Azim E (2014) Presynaptic inhibition of spinal sensory feedback ensures smooth movement. Nature 509:43-48. CrossRef Medline

Flamm RE, Harris-Warrick RM (1986) Aminergic modulation in lobster stomatogastric ganglion: I. Effects on motor pattern and activity of neurons within the pyloric circuit. J Neurophysiol 55:847-865. Medline

Fluhler E, Burnham VG, Loew LM (1985) Spectra, membrane binding, and potentiometric responses of new charge shift probes. Biochemistry 24: 5749-5755. CrossRef Medline

Goaillard JM, Schulz DJ, Kilman VL, Marder E (2004) Octopamine modulates the axons of modulatory projection neurons. J Neurosci 24:70637073. CrossRef Medline

Goeritz ML, Bowers MR, Slepian B, Marder E (2013) Neuropilar projections of the anterior gastric receptor neuron in the stomatogastric ganglion of the Jonah crab, Cancer borealis. PLoS One 8:e79306. CrossRef Medline

Goldsmith CJ, Städele C, Stein W (2014) Optical imaging of neuronal activity and visualization of fine neural structures in non-desheathed nervous systems. PLoS One 9:e103459. CrossRef Medline

Grubb MS, Burrone J (2010) Activity-dependent relocation of the axon initial segment fine-tunes neuronal excitability. Nature 465:1070-1074. CrossRef Medline

Gutierrez GJ, Grashow RG (2009) Cancer borealis stomatogastric nervous system dissection. J Vis Exp 25:e1207. CrossRef Medline

Harris-Warrick RM (2011) Neuromodulation and flexibility in Central Pattern Generator networks. Curr Opin Neurobiol 21:685-692. CrossRef Medline

Hedrich UB, Smarandache CR, Stein W (2009) Differential activation of projection neurons by two sensory pathways contributes to motor pattern selection. J Neurophysiol 102:2866-2879. CrossRef Medline

Kiernan MC, Mogyoros I, Hales JP, Gracies JM, Burke D (1997) Excitability changes in human cutaneous afferents induced by prolonged repetitive axonal activity. J Physiol 500:255-264. CrossRef Medline

Kilman VL, Marder E (1996) Ultrastructure of the stomatogastric ganglion neuropil of the crab, Cancer borealis. J Comp Neurol 374: 362-375. CrossRef Medline

Kole MH, Letzkus JJ, Stuart GJ (2007) Axon initial segment Kv1 channels control axonal action potential waveform and synaptic efficacy. Neuron 55:633-647. CrossRef Medline

Kuba H, Ishii TM, Ohmori H (2006) Axonal site of spike initiation enhances auditory coincidence detection. Nature 444:1069-1072. CrossRef Medline

Kuba H, Oichi Y, Ohmori H (2010) Presynaptic activity regulates $\mathrm{Na}(+)$ channel distribution at the axon initial segment. Nature 465:1075-1078. CrossRef Medline

Kuba H, Adachi R, Ohmori H (2014) Activity-dependent and activityindependent development of the axon initial segment. J Neurosci 34: 3443-3453. CrossRef Medline

Lang PM, Moalem-Taylor G, Tracey DJ, Bostock H, Grafe P (2006) Activity-dependent modulation of axonal excitability in unmyelinated peripheral rat nerve fibers by the $5-\mathrm{HT}(3)$ serotonin receptor. J Neurophysiol 96:2963-2971. CrossRef Medline

Lee SH, Dan Y (2012) Neuromodulation of brain states. Neuron 76: 209-222. CrossRef Medline

Lorincz A, Nusser Z (2008) Cell-type-dependent molecular composition of the axon initial segment. J Neurosci 28:14329-14340. CrossRef Medline

Luján R (2010) Organisation of potassium channels on the neuronal surface. J Chem Neuroanat 40:1-20. CrossRef Medline

Lur G, Higley MJ (2015) Glutamate receptor modulation is restricted to synaptic microdomains. Cell Rep 12:326-334. CrossRef Medline

Maranto AR, Calabrese RL (1984) Neural control of the hearts in the leech, Hirudo medicinalis. J Comp Physiol A 154:367-380. CrossRef Medline

Marder E (1976) Cholinergic motor neurones in the stomatogastric system of the lobster. J Physiol 257:63-86. CrossRef Medline

McGann JP (2013) Presynaptic inhibition of olfactory sensory neurons: new mechanisms and potential functions. Chem Senses 38:459-474. CrossRef Medline

Meyrand P, Weimann JM, Marder E (1992) Multiple axonal spike initiation zones in a motor neuron: serotonin activation. J Neurosci 12:2803-2812. Medline

Mulloney B, Selverston A (1972) Antidromic action potentials fail to 
demonstrate known interactions between neurons. Science 177: 69-72. CrossRef Medline

Norris BJ, Coleman MJ, Nusbaum MP (1994) Recruitment of a projection neuron determines gastric mill motor pattern selection in the stomatogastric nervous system of the crab, Cancer borealis. J Neurophysiol 72: 1451-1463. Medline

Nusbaum MP, Beenhakker MP (2002) A small-systems approach to motor pattern generation. Nature 417:343-350. CrossRef Medline

Nusser Z (2009) Variability in the subcellular distribution of ion channels increases neuronal diversity. Trends Neurosci 32:267-274. CrossRef Medline

Obaid AL, Loew LM, Wuskell JP, Salzberg BM (2004) Novel naphthylstyrylpyridium potentiometric dyes offer advantages for neural network analysis. J Neurosci Methods 134:179-190. CrossRef Medline

Palmer LM, Stuart GJ (2006) Site of action potential initiation in layer 5 pyramidal neurons. J Neurosci 26:1854-1863. CrossRef Medline

Papatheodoropoulos C (2008) A possible role of ectopic action potentials in the in vitro hippocampal sharp wave-ripple complexes. Neuroscience 157:495-501. CrossRef Medline

Pinault D (1990) Antidromic firing occurs spontaneously on thalamic relay neurons: triggering of ectopic action potentials by somatic intrinsic burst discharges. Neuroscience 34:281-292. CrossRef Medline

Pinault D (1995) Backpropagation of action potentials generated at ectopic axonal loci: hypothesis that axon terminals integrate local environmental signals. Brain Res Brain Res Rev 21:42-92. CrossRef Medline

Preuss S, Stein W (2013) Comparison of two voltage-sensitive dyes and their suitability for long-term imaging of neuronal activity. PLoS One 8:e75678. CrossRef Medline

Roeder T (1999) Octopamine in invertebrates. Prog Neurobiol 59:533-561. CrossRef Medline

Schmidt-Hieber C, Jonas P, Bischofberger J (2008) Action potential initiation and propagation in hippocampal mossy fibre axons. J Physiol 586: 1849-1857. CrossRef Medline

Sheffield ME, Best TK, Mensh BD, Kath WL, Spruston N (2011) Slow inte- gration leads to persistent action potential firing in distal axons of coupled interneurons. Nat Neurosci 14:200-207. CrossRef Medline

Shu Y, Duque A, Yu Y, Haider B, McCormick DA (2007) Properties of action-potential initiation in neocortical pyramidal cells: evidence from whole cell axon recordings. J Neurophysiol 97:746-760. CrossRef Medline

Skiebe P, Ganeshina O (2000) Synaptic neuropil in nerves of the crustacean stomatogastric nervous system: an immunocytochemical and electron microscopical study. J Comp Neurol 420:373-397. CrossRef Medline

Smarandache CR, Stein W (2007) Sensory-induced modification of two motor patterns in the crab, Cancer pagurus. J Exp Biol 210:2912-2922. CrossRef Medline

Smarandache CR, Daur N, Hedrich UB, Stein W (2008) Regulation of motor pattern frequency by reversals in proprioceptive feedback. Eur J Neurosci 28:460-474. CrossRef Medline

Städele C, Andras P, Stein W (2012) Simultaneous measurement of membrane potential changes in multiple pattern generating neurons using voltage sensitive dye imaging. J Neurosci Methods 203:78-88. CrossRef Medline

Stein W (2009) Modulation of stomatogastric rhythms. J Comp Physiol A Neuroethol Sens Neural Behav Physiol 195:989-1009. CrossRef Medline

Stein W, Andras P (2010) Light-induced effects of a fluorescent voltagesensitive dye on neuronal activity in the crab stomatogastric ganglion. J Neurosci Methods 188:290-294. CrossRef Medline

Stein W, Schmitz J (1999) Multimodal convergence of presynaptic afferent inhibition in insect proprioceptors. J Neurophysiol 82:512-514. Medline

Stein W, Eberle CC, Hedrich UB (2005) Motor pattern selection by nitric oxide in the stomatogastric nervous system of the crab. Eur J Neurosci 21:2767-2781. CrossRef Medline

Swadlow HA, Kocsis JD, Waxman SG (1980) Modulation of impulse conduction along the axonal tree. Annu Rev Biophys Bioeng 9:143-179. CrossRef Medline

Vacher H, Mohapatra DP, Trimmer JS (2008) Localization and targeting of voltage-dependent ion channels in mammalian central neurons. Physiol Rev 88:1407-1447. CrossRef Medline 